\title{
The Experimental and Numerical Studies on Gas Production from Hydrate Reservoir by Depressurization
}

\author{
Yuhu Bai · Qingping Li · Ying Zhao • \\ Xiangfang Li • Yan Du
}

Received: 14 May 2008 / Accepted: 31 December 2008 / Published online: 24 January 2009

(C) Springer Science+Business Media B.V. 2009

\begin{abstract}
A set of experimental system to study hydrate dissociation in porous media is built and some experiments on hydrate dissociation by depressurization are carried out. A mathematical model is developed to simulate the hydrate dissociation by depressurization in hydrate-bearing porous media. The model can be used to analyze the effects of the flow of multiphase fluids, the kinetic process and endothermic process of hydrate dissociation, ice-water phase equilibrium, the variation of permeability, convection and conduction on the hydrate dissociation, and gas and water productions. The numerical results agree well with the experimental results, which validate our mathematical model. For a 3-D hydrate reservoir of Class 3, the evolutions of pressure, temperature, and saturations are elucidated and the effects of some main parameters on gas and water rates are analyzed. Numerical results show that gas can be produced effectively from hydrate reservoir in the first stage of depressurization. Then, methods such as thermal stimulation or inhibitor injection should be considered due to the energy deficiency of formation energy. The numerical results for 3-D hydrate reservoir of Class 1 show that the overlying gas hydrate zone can apparently enhance gas rate and prolong life span of gas reservoir.
\end{abstract}

Keywords Depressurization - Gas hydrate reservoir - Numerical simulation · Experimental study

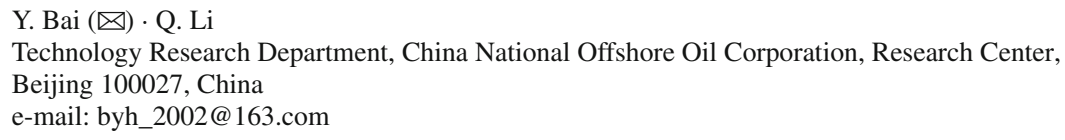

Y. Zhao

Institute of mechanics, Chinese Academy of Sciences, Beijing 100190, China

X. Li

Faculty of Petroleum Engineering, China University of Petroleum, Beijing 102249, China

Y. Du

Guangzhou Institute of Energy Conversion, Chinese Academy of Sciences Guangzhou, 510640 Guangdong, China 


\section{Introduction}

Gas hydrates are ice-like crystalline compounds in which gas molecules are encaged inside voids in a hydrogen-bounded lattice structure of water molecules under suitable conditions of low temperature and high pressure. It is estimated that $90 \%$ of the ocean bottom areas are suitable for hydrate formation, as are regions in and beneath the permafrost, which covers more than $27 \%$ of the earth's surface (Kvenvolden 1998). The most conservative estimate of the total quantity of natural gas in hydrate is two times the energy contents of total fuel fossil reserves recoverable by conventional methods (Burshears et al. 1986). The successful coring of gas hydrate in the South China Sea in 2007 confirmed the existence of hydrate in that ocean area and the present estimate quantity of natural gas reserve in hydrate in the South China Sea is about 60-70 billion tons (Wu and Yao 2008). In terms of characteristics and behavior, hydrate accumulations can be divided into three main classes (Moridis and Timothy 2003). Class1 accumulations include two zones: the hydrate zone with low effective permeability because of high hydrate saturation in the pore space, an underlying two-phase fluid zone with mobile gas. Class 2 deposits feature two zones: a hydrate-bearing zone, overlying a mobile water zone with no free gas. Class 3 accumulations include a single hydrate-bearing zone with the impermeability cover and bottom layers. The Class 1 hydrate reservoir may be the most promising to be exploited first when gas is produced from the gas zone by depressurization. The Messoyakha gas field in Siberia is regarded as Class 1 accumulation in which about $36 \%$ gas production is believed to come from the overlying hydrate dissociation. Some field experiments in Prudhoe bay/Kuparuk river area of the United States, Mallik oil field of Canada, and Nankai trough of Japan have confirmed the existence of Class 1 hydrate reservoir. The gas hydrate accumulations in the South China Sea may belong to the Class 1 accumulations type.

Holder and Patrick (1982) first reported the depressurization process of hydrate reservoir underlain by a gas zone and Burshears et al. (1986) extended Holder's work and offered some qualitative conclusions. However, the models used in their study were some what simple because of the limited understanding on gas hydrate behavior at that time. In recent years, more efforts have been put on gas hydrate and some perfect improvements have been made. The mathematical models used to describe the dissociation process in hydrate bearing porous media are developed from the simple Stefan's equations (Makogon 1997; Ji et al. 2003; Ahmadi et al. 2004; Tsypkin 2001) to the complex model combining multiphase fluids flows and dissociation kinetic process of hydrate (Moridis 2002). Yousif et al. (1991) developed a threephase 1-D model to simulate the process of gas production from Berea sandstone samples containing methane hydrate by depressurization. For the first time, their model coupled the Kim-Bishnoi dissociation kinetic model. Moridis (2002) designed EOSHYDR2 by adding a module for hydrate dissociation into the TOUGH2 general-purpose reservoir simulator. It can model the flow of gas and water, the non-isothermal gas release, and phase behavior. Sun et al. (2005) developed a thermal, three-phase, 1-D model to simulate two regimes of gas production by depressurization: the dissociated-controlled regime and the flow-controlled regime. A dimensionless parameter namely dissociation-flow time-scale ratio was defined and employed to identify the two regimes. At large values, flow is a faster process and the system is increasingly controlled by dissociation; otherwise, the system is controlled by flow. Sun and Kishore (2006) developed a simulator for methane hydrate dissociation in porous media with the ice phase consideration and carried out 1-D and 2-D simulations. However, there was no experimental result found in their study. Tang et al. (2007) investigated 1-D gas hydrate dissociation behavior with the TOUGH-Fx/Hydrate without the ice phase consideration. Nazridoust and Ahmadi (2007) adopted the FLUENT ${ }^{\mathrm{TM}}$ code augmented with 


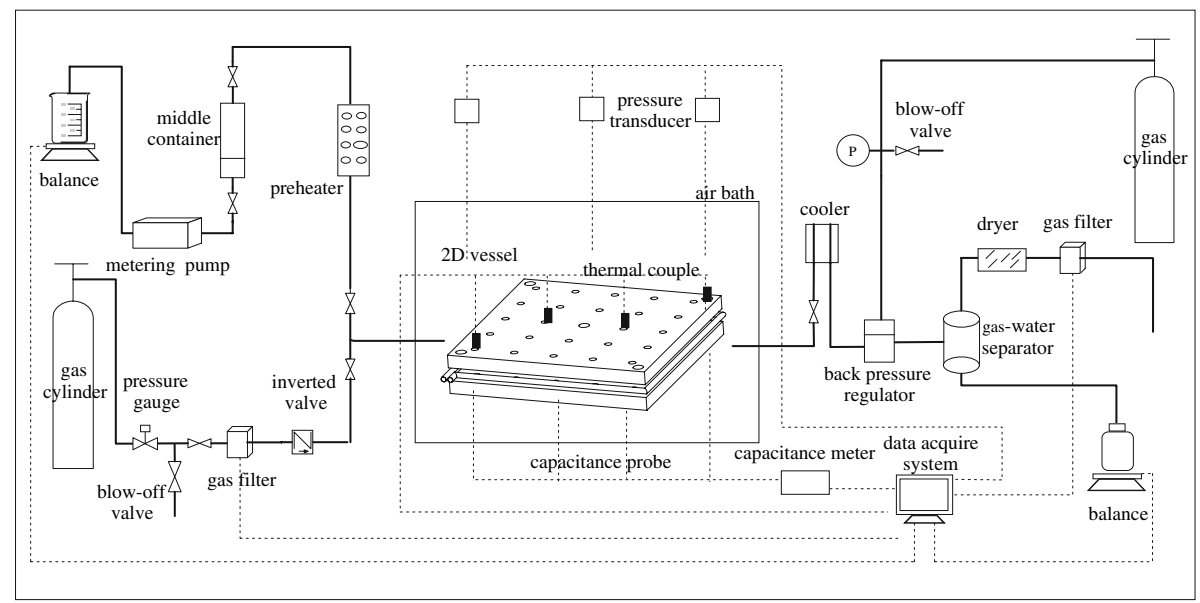

Fig. 1 Schematic diagram of hydrate formation and dissociation experiment system

a newly developed Users' Defined Subroutines (UDS) to formulate and solve an axisymmetric model of the core. The corresponding multiphase gas-liquid flows during hydrate dissociation process were analyzed.

In a word, further effort should be made to improve the gas hydrate dissociation model under depressurization conditions, especially with the effect of water freezing and ice melting on gas production. In this article, gas hydrate dissociation experiments are first performed and then a mathematical model of gas dissociation is developed, in which the effects of multiphase (gas, water, hydrate, ice) flows, the kinetic process and endothermic process of hydrate dissociation, the variation of permeability, convection and conduction, the phase variation of hydrate, and ice on hydrate dissociation, and gas and water productions are considered. Then, the numerical results are compared with experiments to verify the mathematical and numerical models. Based on that, the dynamic process of gas production from Class 1 and Class 3 hydrate accumulations is studied.

\section{Experiment Description}

A set of experimental system used in this study for hydrate formation and dissociation was built in the Guangzhou Center for Gas Hydrate Research, Chinese Academy of Sciences. The schematic diagram of the experimental system is shown in Fig. 1. It consists of seven units such as stable liquid and gas supplying, hydrate formation and dissociation, environment simulation, the backpressure regulator controlling, and computation and data acquisition units. The most important unit in this system is the hydrate formation and dissociation unit, which is a stainless vessel with length, width, and thickness of $380 \mathrm{~mm}, 380 \mathrm{~mm}$, and $18 \mathrm{~mm}$, respectively. It can be operated up to $15 \mathrm{MPa}$ and is set in a big box with an air-conditioned equipment at a temperature range from $-20^{\circ} \mathrm{C}$ to $80^{\circ} \mathrm{C}$. Twenty-five temperature sensors are evenly arranged on one side of the stainless vessel in a manner of $5 \times 5$. On the other side of the vessel at the positions corresponding to temperature sensors, 25 capacitance units are laid to measure the capacitance between any two of them, with which the distribution variation of gas hydrate saturation with time and space can be detected. Three pressure sensors are 


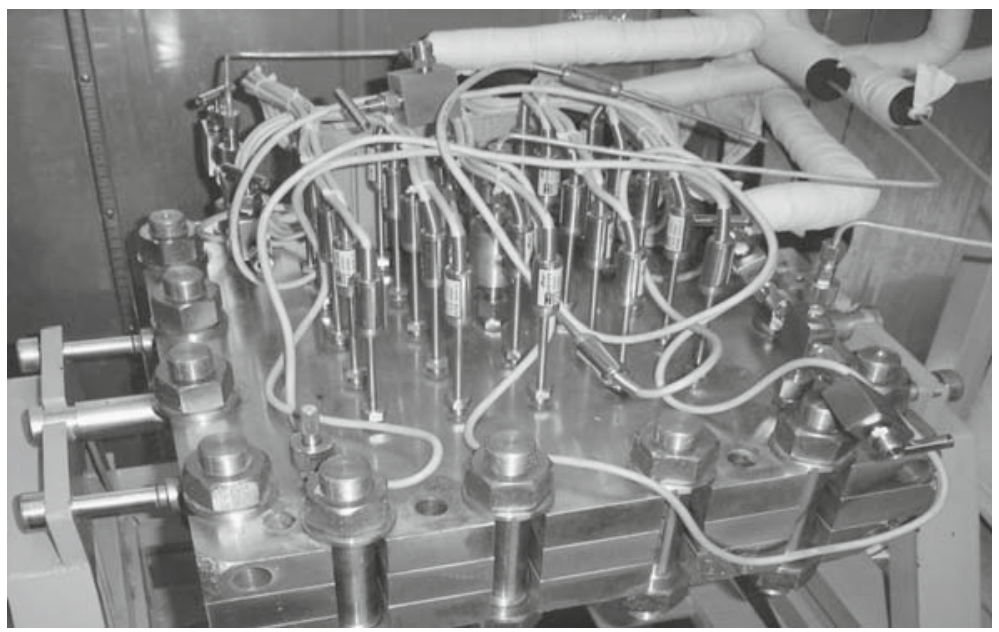

Fig. 2 Photograph of hydrate formation and dissociation unit

evenly installed along the vessel diagonal with one of them located at the center and the other two at respective corner ports. A photograph of the vessel is shown in Fig. 2. The data acquisition unit can record all the information varying with time, which includes the pressure, temperature, gas/water injection rate, and gas/water production rate. With this experimental system, the formation of gas hydrates in porous media and their dissociation in the case of depressurization, thermal stimulation, and inhibitor injection can be achieved.

During each experimental run, the dry sands are sieved into the size range of 300-450 $\mu \mathrm{m}$ and are pushed tightly into the vessel, resulting in the sediment with porosity around $40 \%$ and permeability of 1.97 darcy. The outlet valve is closed and the vessel is saturated with distilled water with a metering pump. Methane gas is then injected slowly up to a pressure that is sufficiently higher than the equilibrium pressure at the working temperature. At the same time, the data acquisition unit is started to acquire the data. The amount of injected distilled water and methane gas is recorded. The vessel is then closed and kept at a steady environmental temperature for more than $24 \mathrm{~h}$ to be certain that there was no leakage from the system. Then the temperature of the air bath is decreased to the working temperature. With the decrease of temperature in the vessel, the pressure in the vessel begins to reduce which means the formation of gas hydrates in porous media. When the pressure in the vessel stops decreasing and maintains to a steady value, the formation process of hydrates usually lasting for 2-3 days is completed. In the dissociation process, the temperature is kept invariably and the outlet valve is opened to lower the backpressure to a designed value that is lower than the equilibrium pressure at working temperature. The variations of such parameters as hydrate saturation, pressure, temperature, and water and gas rates with time are recorded.

\section{Mathematical Models}

In our model, three components (hydrate, methane, and water) and four phases (gas, water, hydrate, and ice) are considered. A three dimensional hydrate-bearing reservoir with length $\mathrm{L}$, width $\mathrm{W}$ and thickness $\mathrm{H}$ is considered. In addition, some assumptions are made as follows: (1) the gas contained in hydrate is only methane, namely the gas hydrate in our assumed 
reservoir is SI type; (2) the ice phase contains only water component, water phase contains only water; (3) Darcy's law is valid for water and gas phases; (4) the diffusion and the dispersion are neglected in mass transportation. With these concerned, the mass balance equations of gas, water, and ice and hydrate phases are, respectively, given by

$$
\begin{gathered}
\frac{\partial\left(\phi \rho_{\mathrm{g}} s_{\mathrm{g}}\right)}{\partial t}=\nabla \cdot\left(\frac{\rho_{\mathrm{g}} k_{\mathrm{g}}}{\mu_{\mathrm{g}}} \nabla p_{\mathrm{g}}\right)+\dot{m}_{\mathrm{g}}+q_{\mathrm{g}}, \\
\frac{\partial}{\partial t}\left[\phi\left(\rho_{\mathrm{w}} s_{\mathrm{W}}+\rho_{\mathrm{I}} s_{\mathrm{I}}\right)\right]=\nabla \cdot\left(\frac{\rho_{\mathrm{w}} k_{\mathrm{w}}}{\mu_{\mathrm{w}}} \nabla p_{\mathrm{w}}\right)+\dot{m}_{\mathrm{w}}+q_{\mathrm{w}}, \\
-\dot{m}_{\mathrm{h}}=\frac{\partial\left(\phi \rho_{\mathrm{h}} s_{\mathrm{h}}\right)}{\partial t} .
\end{gathered}
$$

Here, $\rho$ and $s$ are the density and viscosity, respectively. The subscripts $h, g, w$, and $I$ denote hydrate, gas, water, and ice phases, respectively. $\phi$ is the porosity; $p_{\mathrm{w}}$ and $p_{\mathrm{g}}$ are the pressures of water and gas phases, respectively; $k_{\mathrm{g}}$ and $k_{\mathrm{w}}$ are the permeabilities of gas and water phases, respectively; $\mu_{\mathrm{w}}$ and $\mu_{\mathrm{g}}$ are the viscosities of water and gas phases, respectively; $\dot{m}_{\mathrm{h}}, \dot{m}_{\mathrm{g}}$, and $\dot{m}_{\mathrm{w}}$ are the corresponding local mass rates of hydrate, gas and water produced per unit volume, respectively; $\dot{m}_{\mathrm{I}}$ is the mass rate of ice melting or freezing per unit volume. $q_{\mathrm{g}}$ and $q_{\mathrm{w}}$ are written as

$$
\begin{gathered}
q_{\mathrm{g}}=\frac{\pi \rho_{\mathrm{g}} k_{\mathrm{g}}\left(p_{\mathrm{f}}-p_{\mathrm{g}}\right)}{2 \mu_{\mathrm{g}} \ln r_{\mathrm{ew}} / r_{\mathrm{w}}} \delta\left(x-x_{0}, y-y_{0}, z-z_{0}\right), \\
q_{\mathrm{w}}=\frac{\pi \rho_{\mathrm{w}} k_{\mathrm{w}}\left(p_{\mathrm{f}}-p_{\mathrm{w}}\right)}{2 \mu_{\mathrm{w}} \ln r_{\mathrm{ew}} / r_{\mathrm{w}}} \delta\left(x-x_{0}, y-y_{0}, z-z_{0}\right),
\end{gathered}
$$

in which $p_{\mathrm{f}}$ denotes the bottom pressure of the production well; $r_{\mathrm{w}}$ and $r_{\mathrm{ew}}$ the well and supply radii, respectively; $\delta(x, y, z)$ the Dirac function; $x_{0}, y_{0}$, and $z_{0}$ the coordinates of production well.

The energy balance equation can be read as follows:

$$
\begin{aligned}
\frac{\partial}{\partial t}\left(C_{t} T\right)= & -\nabla \cdot\left(T \rho_{\mathrm{w}} C_{\mathrm{w}} \mathrm{u}_{\mathrm{w}}\right)-\nabla \cdot\left(T \rho_{\mathrm{g}} C_{\mathrm{pg}} \mathrm{u}_{\mathrm{g}}\right)+\nabla \cdot\left(K_{t} \nabla T\right)-\dot{m}_{\mathrm{h}} \Delta H_{\mathrm{h}} \\
& +\dot{m}_{\mathrm{I}} \Delta H_{\mathrm{I}}+q_{\mathrm{e}},
\end{aligned}
$$

where

$$
\begin{aligned}
& C_{t}=\phi\left(\rho_{\mathrm{w}} s_{\mathrm{w}} C_{\mathrm{w}}+\rho_{\mathrm{g}} s_{\mathrm{g}} C_{\mathrm{Vg}}+\rho_{\mathrm{h}} s_{\mathrm{h}} C_{\mathrm{h}}+\rho_{\mathrm{I}} s_{\mathrm{I}} C_{\mathrm{I}}\right)+\rho_{\mathrm{r}} C_{\mathrm{r}}(1-\phi), \\
& K_{t}=\phi\left(s_{\mathrm{W}} K_{\mathrm{w}}+s_{\mathrm{g}} K_{\mathrm{g}}+s_{\mathrm{h}} K_{\mathrm{h}}+s_{\mathrm{I}} K_{\mathrm{I}}\right)+(1-\phi) K_{\mathrm{r}}, \\
& \mathrm{u}_{\mathrm{w}}=-\frac{k_{\mathrm{w}}}{\mu_{\mathrm{w}}} \nabla p_{\mathrm{w}}, \quad \mathrm{u}_{\mathrm{g}}=-\frac{k_{\mathrm{g}}}{\mu_{\mathrm{g}}} \nabla p_{\mathrm{g}} .
\end{aligned}
$$

Here, $C_{\mathrm{w}}, C_{\mathrm{h}}, C_{\mathrm{r}}, C_{\mathrm{I}}, C_{\mathrm{Vg}}$, and $C_{\mathrm{pg}}$ are the specific heats of water, hydrate, rock, ice, the constant volume and pressure specific heats, respectively; $K_{\mathrm{W}}, K_{\mathrm{g}}, K_{\mathrm{r}}, K_{\mathrm{h}}$, and $K_{\mathrm{I}}$ the coefficients of thermal conductivity of water, gas, porous media, hydrate, and ice, respectively; $\Delta H_{\mathrm{h}}$ and $\Delta H_{\mathrm{I}}$ are the enthalpy changes in hydrate dissociation and ice melting or freezing, respectively; $q_{\mathrm{e}}$ the energy conducted through cap and bottom formation.

The relationship of saturation satisfies

$$
s_{\mathrm{W}}+s_{\mathrm{g}}+s_{\mathrm{h}}+s_{\mathrm{I}}=1 .
$$


The water and gas pressures are related according to the capillary force equation:

$$
p_{\mathrm{c}}=p_{\mathrm{w}}-p_{\mathrm{g}}
$$

In our model, the porous media and water are regarded to be slightly compressive, and their state equations are given by

$$
\rho_{\mathrm{w}}=\rho_{\mathrm{w} 0}\left(1+c_{\mathrm{w}}\left(p_{\mathrm{w}}-p_{\mathrm{w} 0}\right)\right), \quad \phi=\phi_{0}\left(1+c_{\phi}\left(\frac{p_{\mathrm{w}}+p_{\mathrm{g}}}{2}-\frac{p_{\mathrm{w} 0}+p_{\mathrm{g} 0}}{2}\right)\right),
$$

where $c_{\mathrm{w}}$ and $c_{\phi}$ are the coefficients of compressibility of water and porous media, respectively; $p_{\mathrm{w} 0}$ and $p_{\mathrm{g} 0}$ the reference pressures of water and gas, respectively.

The state equation of gas is

$$
p_{\mathrm{g}} V=\frac{m}{M} Z R T
$$

where $Z$ is the gas deviation factor, $m$ the mass of the gas, $V$ the gas volume, and $R$ the universal gas constant. Then we obtain the gas compressibility $c_{g}$ as follows:

$$
c_{\mathrm{g}}=\frac{1}{\rho_{\mathrm{g}}} \frac{\mathrm{d} \rho_{\mathrm{g}}}{\mathrm{d} p_{\mathrm{g}}}=\left(\frac{1}{p_{\mathrm{g}}}-\frac{1}{Z} \frac{\mathrm{d} Z}{\mathrm{~d} p_{\mathrm{g}}}\right) .
$$

The boundary conditions are

$$
\begin{aligned}
& p(0,0,0, t)=p_{\mathrm{gp}}, \quad T(0,0,0, t)=T_{\mathrm{gp}}, \\
& \rho_{\mathrm{g}} v_{\mathrm{gn}}=0, \quad \rho_{\mathrm{w}} v_{\mathrm{wn}}=0, \quad(\mathrm{n}=x, y, z),
\end{aligned}
$$

and the initial conditions are

$$
\left.p_{\mathrm{g}}\right|_{t=0}=p_{\mathrm{i}},\left.\quad s_{\mathrm{h}}\right|_{t=0}=s_{\mathrm{hi}},\left.\quad s_{\mathrm{wi}}\right|_{t=0}=s_{\mathrm{wi}},\left.\quad T\right|_{t=0}=T_{\mathrm{i}},
$$

where $p_{\mathrm{i}}, s_{\mathrm{hi}}, s_{\mathrm{wi}}$, and $T_{\mathrm{i}}$ are the initial distributions of gas pressure, hydrate saturation, water saturation, and temperature, respectively; $p_{\mathrm{gp}}$ and $T_{\mathrm{gp}}$ are the pressure and temperature on the bottom of production well, respectively, and $v_{\mathrm{gn}}$ and $v_{\mathrm{wn}}$ are the gas and water velocities in normal direction on the boundary, respectively.

In addition, some additional expressions are needed to describe the particular characteristics of gas hydrate dissociation in porous media.

\subsection{Dissociation Kinetic Model of Gas Hydrate}

The Kim-Bishnoi model is adopted to evaluate the local mass rate of gas generated by hydrate dissociation as follows (Kim et al. 1987)

$$
\dot{m}_{\mathrm{g}}=k_{\mathrm{d}} A_{\mathrm{s}}\left(f_{\mathrm{eq}}-f\right),
$$

in which

$$
k_{d}=k_{0 i} e^{-\frac{\Delta E_{a}}{R T}} .
$$

Here $A_{\mathrm{S}}$ is the specific surface area of porous media bearing gas hydrate; $f$ is the local gas fugacity; $f_{\mathrm{eq}}$ is the gas equilibrium fugacity; $k_{0 \mathrm{i}}$ is the intrinsic dissociation constant that equals to $3.6 \times 10^{4} \mathrm{~mol} /\left(\mathrm{m}^{2} \cdot \mathrm{Pa} \cdot \mathrm{s}\right)$, and $\Delta E_{\mathrm{a}}$ the activation energy of hydrate dissociation given by $\Delta E_{\mathrm{a}} / R=9752.73 \mathrm{~K}$. 


\subsection{Absolute Permeability Model}

During the gas hydrate dissociation, the volume occupied by the gas and water continuously varies with time, which leads to the variation of the absolute permeability. The power-law model proposed by Civan (2001) is used to describe the variation of the local absolute permeability

$$
\frac{k}{k_{0}}=\frac{\phi_{\mathrm{e}}}{\phi_{0}}\left(\frac{\phi_{\mathrm{e}}\left(1-\phi_{0}\right)}{\phi_{0}\left(1-\phi_{\mathrm{e}}\right)}\right)^{2 \beta},
$$

where $k$ is the scalar value of local absolute permeability; $\phi_{0}$ is the total porosity; $k_{0}$ is the reference absolute permeability corresponding to $\phi_{0} ; \phi_{\mathrm{e}}$ is the effective porosity defined as $\phi_{\mathrm{e}}=\phi_{0}\left(1-s_{\mathrm{h}}-s_{\mathrm{I}}\right)$, where the effect of saturations of water and ice phases on permeability is considered; $\beta$ is the index parameter. As the value of $\beta$ increases, $k$ decreases faster with $\phi_{\mathrm{e}}$.

\subsection{Relative Permeability and Capillary Models}

The relative permeability and capillary pressure are considered with the modification of Brooks-Corey model (Lake 1989)

$$
\begin{gathered}
k_{\mathrm{rg}}=k_{\mathrm{rg}}^{0}\left(s_{\mathrm{g}}^{\mathrm{e} *}\right)^{n_{\mathrm{G}}}, \quad k_{\mathrm{rw}}=k_{\mathrm{rw}}^{0}\left(s_{\mathrm{w}}^{\mathrm{e} *}\right)^{n_{\mathrm{W}}}, \\
p_{\mathrm{c}}=p_{\mathrm{ce}}\left(s_{\mathrm{w}}^{\mathrm{e} *}\right)^{-n_{\mathrm{c}}},
\end{gathered}
$$

where $k_{\mathrm{rg}}^{0}$ and $k_{\mathrm{rw}}^{0}$ are the endpoint values of gas and water relative permeability, respectively; $n_{\mathrm{G}}$ and $n_{\mathrm{W}}$ are the exponential parameters for gas and water phases, respectively; $p_{\mathrm{ce}}$ is the entry capillary pressure, and $n_{\mathrm{c}}$ is the exponential parameter that describes the pore structure. With gas hydrate consideration, the saturations of water and gas are modified as follows:

$$
\begin{gathered}
s_{\mathrm{g}}^{\mathrm{e} *}=\frac{s_{\mathrm{g}}^{\mathrm{e}}-s_{\mathrm{gr}}^{\mathrm{e}}}{1-s_{\mathrm{wr}}^{\mathrm{e}}-s_{\mathrm{gr}}^{\mathrm{e}}}, \quad s_{\mathrm{w}}^{\mathrm{e} *}=\frac{s_{\mathrm{W}}^{\mathrm{e}}-s_{\mathrm{wr}}^{\mathrm{e}}}{1-s_{\mathrm{wr}}^{\mathrm{e}}-s_{\mathrm{gr}}^{\mathrm{e}}}, \quad s_{\mathrm{g}}^{\mathrm{e}}=\frac{s_{\mathrm{g}}}{s_{\mathrm{g}}+s_{\mathrm{w}}}, \quad s_{\mathrm{w}}^{\mathrm{e}}=\frac{s_{\mathrm{W}}}{s_{\mathrm{g}}+s_{\mathrm{W}}}, \\
s_{\mathrm{gr}}^{\mathrm{e}}=\frac{s_{\mathrm{gr}}}{s_{\mathrm{g}}+s_{\mathrm{w}}}, \quad s_{\mathrm{wr}}^{\mathrm{e}}=\frac{s_{\mathrm{wr}}}{s_{\mathrm{g}}+s_{\mathrm{w}}} .
\end{gathered}
$$

\subsection{The Phase Equilibrium Model}

The gas hydrate equilibrium equation can be read as (Moridis 2002)

$$
p_{\mathrm{e}}=\left\{\begin{array}{ll}
\exp (-43.8921173434628+0.776302133739303 T \\
-7.27291427030502 \times 10^{-3} T^{2}+3.85413985900724 \times 10^{-5} T^{3} & \\
\left.-1.03669656828834 \times 10^{-7} \times T^{4}+1.09882180475307 \times 10^{-10} \times T^{5}\right) & T<273.15 \mathrm{~K} \\
\exp \left(-1.9413850446456 \times 10^{5}+3.31018213397926 \times 10^{3} T\right. & T \geq 273.15 \mathrm{~K} \\
-22.5540264493806 T^{2}+0.0767559117787059 T^{3} & \\
\left.-1.30465829788791 \times 10^{-4} T^{4}+8.8606531668757 \times 10^{-8} T^{5}\right) &
\end{array} .\right.
$$

The effect of pressure on water-ice phase equilibrium is little because the magnitude range of pressure in sediment with the existence of gas hydrate is from $10^{6} \mathrm{~Pa}$ to $10^{7} \mathrm{~Pa}$ (Sloan 1998). Therefore, the water-ice phase equilibrium equation can be simplified as

$$
T=T_{\mathrm{qp}} .
$$


In the case of the existence of ice, the possible phase combination statuses can be icehydrate $(\mathrm{I}+\mathrm{H})$, gas-ice $(\mathrm{G}+\mathrm{I})$, gas-ice-hydrate $(\mathrm{G}+\mathrm{I}+\mathrm{H})$, water-hydrate $(\mathrm{W}+\mathrm{H})$, water-gas-hydrate $(\mathrm{W}+\mathrm{G}+\mathrm{H})$, water-ice-hydrate $(\mathrm{W}+\mathrm{I}+\mathrm{H})$, water-ice-gas $(\mathrm{W}+\mathrm{I}+\mathrm{G})$, and water-gas-hydrate-ice $(\mathrm{W}+\mathrm{G}+\mathrm{H}+\mathrm{I})$, etc. We can see that the appearance of ice phase complicates the problem.

\subsection{The Endothermic Model of Hydrate Dissociation}

The process of hydrate dissociation is an endothermic phase change process. The latent heat for per kilogram of hydrate in $\mathrm{J} / \mathrm{kg}$ is given by (Kamath 1983)

$$
\Delta H=A T+B
$$

where $A$ and $B$ are constants given by $A=-1,050 \mathrm{~J} /(\mathrm{kg} \cdot \mathrm{K})$ and $B=3,527,000 \mathrm{~J} / \mathrm{kg}$.

\section{Numerical Solution and Verification of Mathematical Model}

With water freezing and ice melting consideration, many phase combination statuses are involved in the hydrate dissociation system. The traditional simulation method, in which the unknowns are usually the same for each grid block at different times, is not the best choice under our hydrate system concerned. Therefore, the primary variable switch method (PVSM) is introduced to track the phase transition between water and ice phases (Sun and Kishore 2006). The primary variables are defined as the unknowns that are to be solved directly from the governing equations. For each grid block, the primary variables are chosen from such usual variables as pressure, temperature, and phase saturations. In the depressurization system of gas hydrate dissociation, the pressure of gas phase is always chosen as a primary variable. The primary variables of phase saturations (water, gas, hydrate, and ice) are determined according to the phase combination status. The primary variables are switched according to the phase status and the switch is necessitated by the phase transition between water and ice phases. Table 1 presents the phase status and its corresponding primary variables in the water-rich phase.

In each time step, the phase status of each grid block is determined according to the results of the previous time step. Therefore, the primary variables in current time step can be chosen according to Table 1 and the corresponding governing equations are also determined. When the phase status of grid blocks is switched to Pha1, the governing equations of these grid blocks include Eqs. 1, 2, 3, and 4, in which the effect of ice phase disappears. When the phase status of grid blocks is switched to Pha2, the relevant governing equations of these grid blocks are Eqs. 1, 2, and 3. When the phase status of grid blocks is switched to Pha3, the governing equations corresponding to these grid blocks are Eqs. 1, 2, 3, and 4, in which the effect of water phase does not need to be considered. The finite difference method is used to

Table 1 The phase statuses and their corresponding primary variables in water phase

\begin{tabular}{lll}
\hline Case & $\begin{array}{l}\text { Phase statuses } \\
\text { (water-rich phase) }\end{array}$ & Primary variables \\
\hline Pha1 & water $(\mathrm{W})$ & $p_{\mathrm{g}}, s_{\mathrm{W}}, s_{\mathrm{h}}, T$ \\
Pha2 & water-ice $(\mathrm{W}+\mathrm{I})$ & $p_{\mathrm{g}}, s_{\mathrm{W}}, s_{\mathrm{h}}, s_{\mathrm{I}}$ \\
Pha3 & ice(I) & $p_{\mathrm{g}}, s_{\mathrm{h}}, s_{\mathrm{I}}, T$ \\
\hline
\end{tabular}


Table 2 Main physical variable values determined by experiment

\begin{tabular}{lll}
\hline Physical variable values & 1-D system & 2-D system \\
\hline Absolute permeability (d) & 1.11 & 1.97 \\
Porosity & 0.328 & 0.4 \\
Initial pressure $(\mathrm{MPa})$ & 3.535 & 3.24 \\
Initial temperature $\left({ }^{\circ} \mathrm{C}\right)$ & 1.04 & 1.7 \\
Backpressure $(\mathrm{MPa})$ & 0.93 & 2.25 \\
Initial water saturation & 0.296 & 0.389 \\
Initial hydrate saturation & 0.218 & 0.176 \\
\hline
\end{tabular}

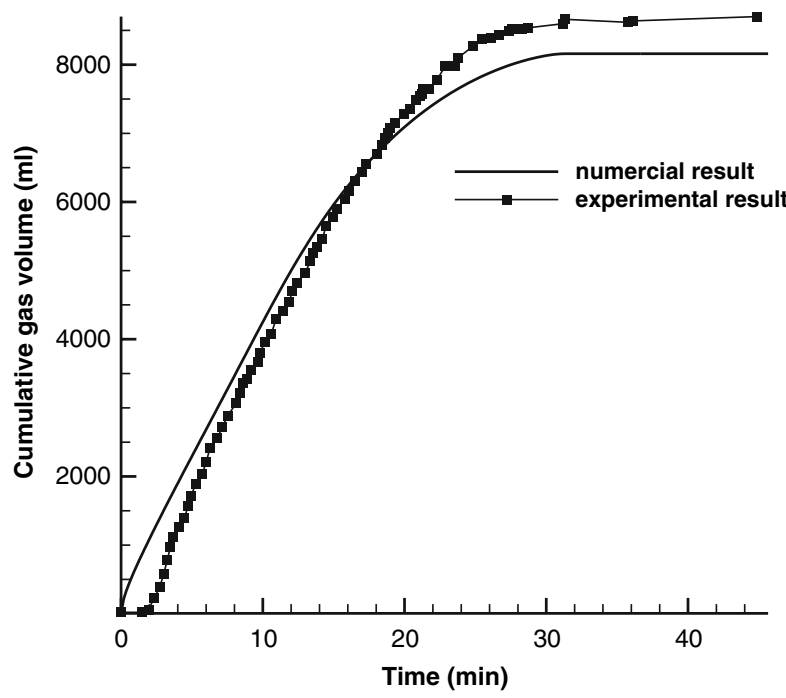

Time (min)
Fig. 3 Comparison of cumulative gas volumes of numerical and experimental results for 1-D model

discretize the governing equations. The convection terms are discretized with the upstream scheme and the diffusion terms with the second-order central difference scheme. The hydrate saturation is first solved explicitly; then the pressure is solved implicitly, followed by explicit solution of the water saturation. Finally, the temperature is implicitly solved. The detailed algebra equations and solution procedures can be seen in our previous published study (Bai et al. 2007).

To verify the mathematical model and numerical solution, the numerical results of 1- and 2-D hydrate dissociation systems by depressurization are compared with experimental results. Both the 2-D experimental results and the 1-D experimental results are obtained by us at he Guangzhou Center for Gas Hydrate Research, Chinese Academy of Sciences but not in our mentioned experimental system. The detailed information on 1-D hydrates formation and dissociation experiment system can be found in Tang's article (Tang et al. 2007). The main physical variable values used in 1- and 2-D models in numerical simulation are listed in Table 2 in which the values are determined by experiments. Figures 3 and 4 show the comparisons of cumulative gas volume and temperatures between numerical and experimental results for 1-D gas hydrate dissociation system under depressurization condition. Figures 5 and 6 show the comparisons of gas rate and pressure of numerical and experimental results for 2-D gas hydrate dissociation system under depressurization condition. We can see that the numerical results agree well with the experiments not only in 1-D, but also in 2-D system, which completes the validation of the mathematical model and numerical codes employed. 
Fig. 4 Comparison of temperature of numerical and experimental results for $1-\mathrm{D}$ model
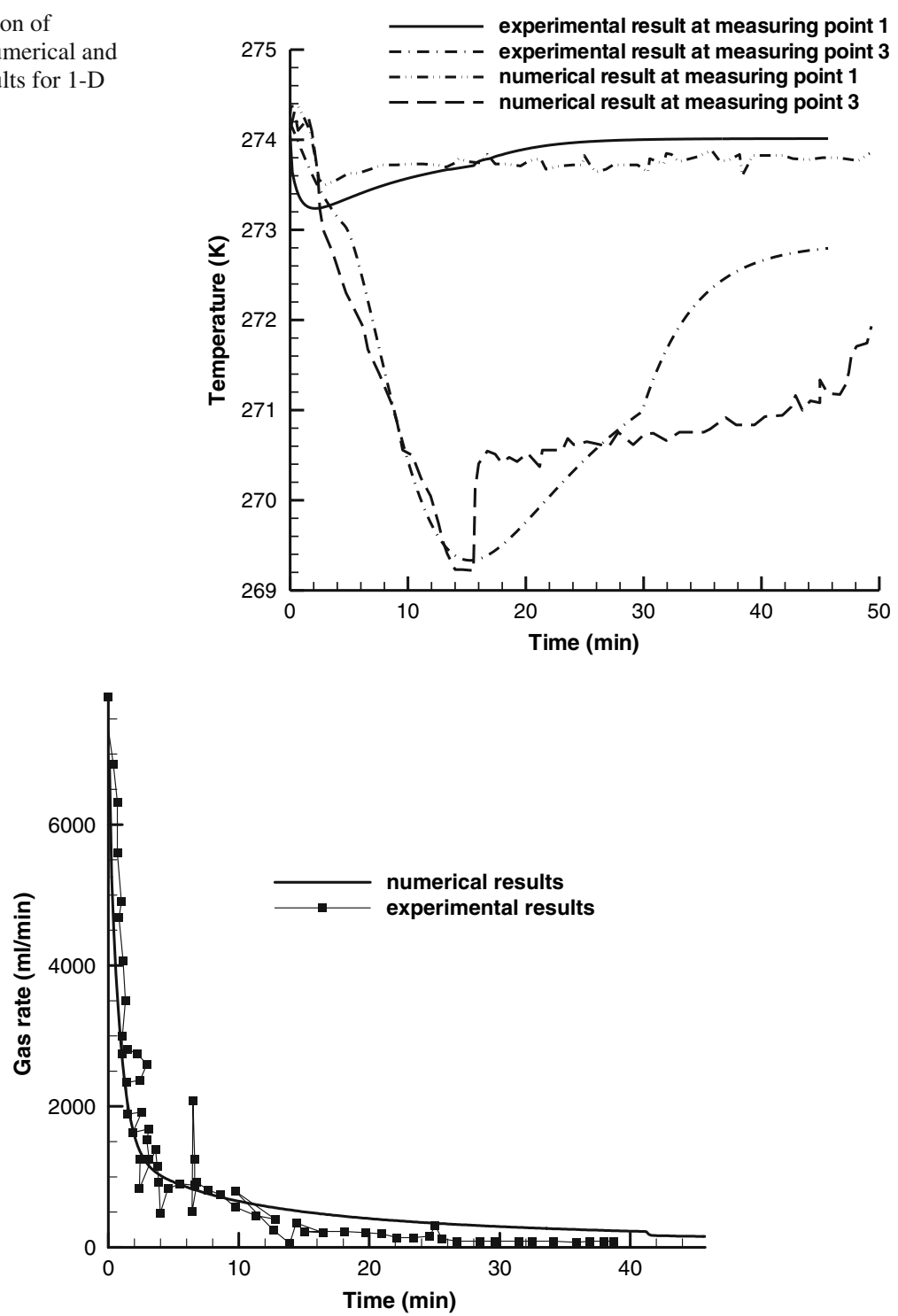

Fig. 5 Comparison of gas rates of numerical and experimental results for 2-D model

\section{Simulation on 3-D Hydrate Reservoir of Class 3}

\subsection{Dynamic Process of Hydrates Dissociation}

To clarify the dynamic process of hydrates dissociation in filed scale, let us first consider a 3-D gas hydrate reservoir of Class 3 with impermeability cap and bottom layers. Its main physical parameter values are listed in Table 3 .

Figure 7 shows the spatial distributions of pressure, temperature, and saturations of water, gas, ice, and hydrate on the 46th day for the 3-D hydrate reservoir of Class 3 produced by 
Fig. 6 Comparison of pressures of numerical and experimental results for 2-D model

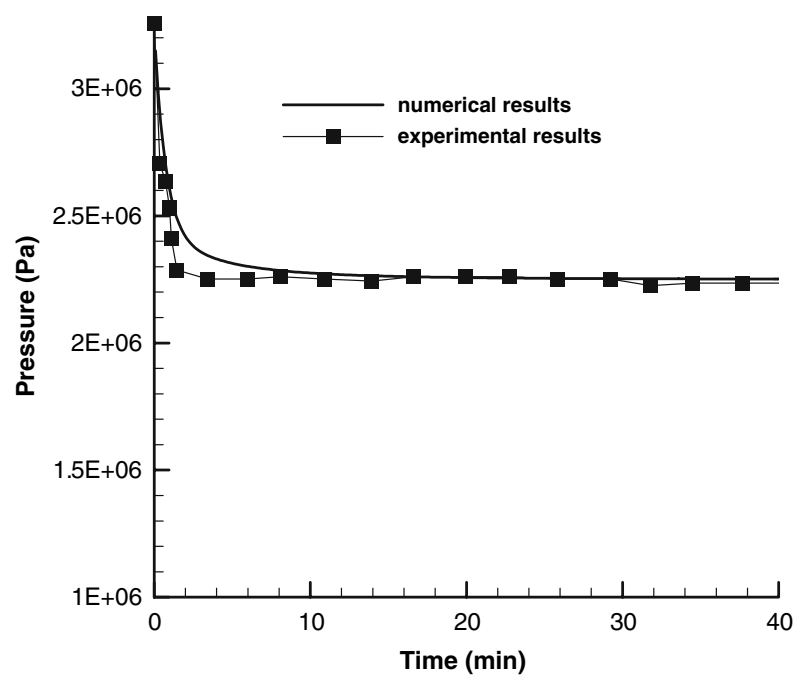

Table 3 The values of main physical variables

\begin{tabular}{llll}
\hline Physical variables & Values & Physical variables & Values \\
\hline$c_{\mathrm{W}}(1 / \mathrm{Pa})$ & $5.0 \mathrm{e}-10$ & $n_{\mathrm{G}}$ & 1.5 \\
$c_{\phi}(1 / \mathrm{Pa})$ & $8.0 \mathrm{e}-10$ & $n_{\mathrm{W}}$ & 4.0 \\
$K_{\mathrm{W}}(\mathrm{W} /(\mathrm{K} \cdot \mathrm{m}))$ & 0.56 & $\beta$ & 3.0 \\
$K_{\mathrm{g}}(\mathrm{W} /(\mathrm{K} \cdot \mathrm{m}))$ & 0.07 & $\phi_{0}$ & 0.3 \\
$K_{\mathrm{r}}(\mathrm{W} /(\mathrm{K} \cdot \mathrm{m}))$ & 3 & $k_{0}\left(\mathrm{~m}^{2}\right)$ & $3.97 \mathrm{e}-13$ \\
$K_{\mathrm{h}}(\mathrm{W} /(\mathrm{K} \cdot \mathrm{m}))$ & 0.49 & $s_{\mathrm{Wi}}$ & 0.2 \\
$K_{\mathrm{I}}(\mathrm{W} /(\mathrm{K} \cdot \mathrm{m}))$ & 3.4 & $s_{\mathrm{hi}}$ & 0.62 \\
$C_{\mathrm{W}}(\mathrm{J} /(\mathrm{kg} \cdot \mathrm{K}))$ & 4,211 & $p_{\mathrm{i}}(\mathrm{Pa})$ & $6.0 \mathrm{e}+6$ \\
$C_{\mathrm{r}}(\mathrm{J} /(\mathrm{kg} \cdot \mathrm{K}))$ & 840 & $p_{\mathrm{gp}}(\mathrm{Pa})$ & $1.0 \mathrm{e}+6$ \\
$C_{\mathrm{h}}(\mathrm{J} /(\mathrm{kg} \cdot \mathrm{K}))$ & 1,800 & $\rho_{\mathrm{I}}\left(\mathrm{kg} / \mathrm{m}^{3}\right)$ & 900 \\
$C_{\mathrm{Vg}}(\mathrm{J} /(\mathrm{kg} \cdot \mathrm{K}))$ & 2,206 & $\rho_{\mathrm{r}}\left(\mathrm{kg} / \mathrm{m}^{3}\right)$ & $2.5 \mathrm{e}+3$ \\
$C_{\mathrm{I}}(\mathrm{J} /(\mathrm{kg} \cdot \mathrm{K}))$ & 2,100 & $\mu_{\mathrm{g}}(\mathrm{Pa} \cdot \mathrm{s})$ & $1.0 \mathrm{e}-5$ \\
$T_{\mathrm{i}}(\mathrm{K})$ & 280.0 & $r_{\mathrm{g}}(\mathrm{m})$ & 0.1 \\
$T_{\mathrm{gp}}(\mathrm{K})$ & 280.0 & $\rho_{\mathrm{h}}\left(\mathrm{kg} / \mathrm{m}^{3}\right)$ & 910 \\
$\rho_{\mathrm{W}}\left(\mathrm{kg} / \mathrm{m}^{3}\right)$ & 1,000 & $\mu_{\mathrm{W}}(\mathrm{Pa} \cdot \mathrm{s})$ & $1.0 \mathrm{e}-3$ \\
\hline
\end{tabular}

depressurization in which the production well is located at the corner of the left hand side. We can see from these pictures that with the depletion of pressure in the hydrate-bearing formation, hydrates dissociate, temperature falls, gas and water saturations rise, and ice appears in the formation near the production well.

Figures 8 and 9 show the variations of gas and water rates with time for a 3-D hydrate reservoir of Class 3 under depressurization. Obviously, the gas rate can be divided into three stages as follows. In the first stage, from the beginning of the depressurization to the 10th day in this case, gas rate increases rapidly. In this stage, large pressure gradient induced by the low pressure at the bottom of the production well drives much free initial gas flow into the well. On the other hand, enough energy can be supplied from the initial sensible heat of surroundings for gas hydrate dissociation, which causes initially rapid dissociation of gas hydrate. In the second stage which lasts for a relative long period, from the 10th day to the 80th day in this case, gas rate decreases slowly. The reasons can be generalized into 

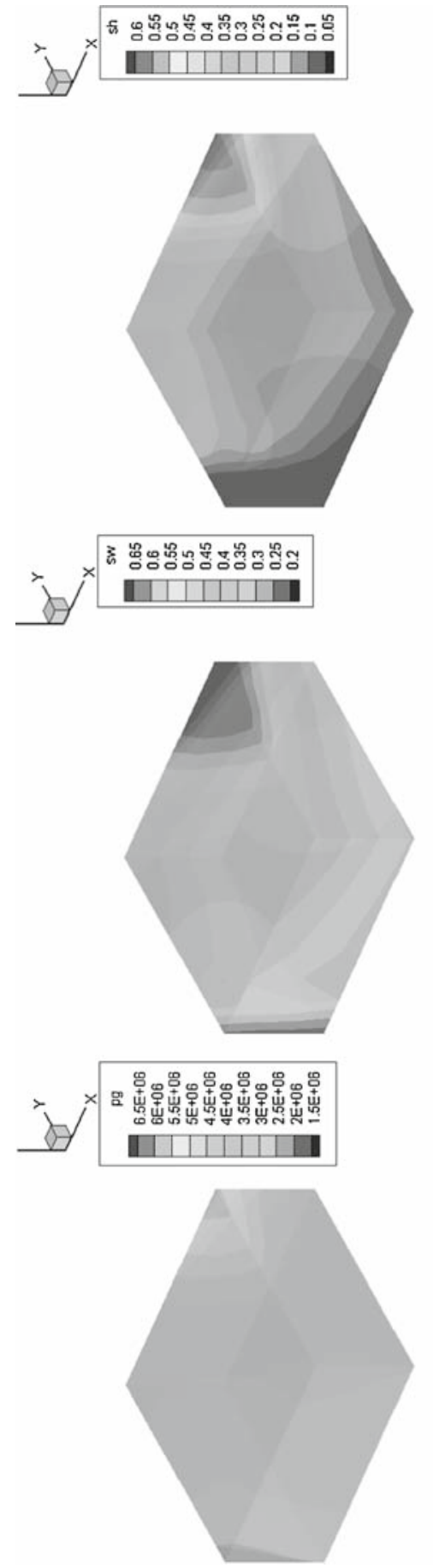
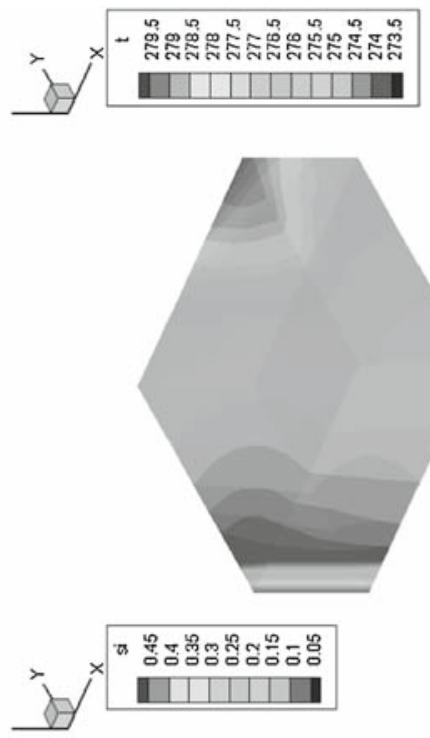

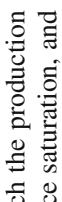

을

.

홀

胥

골

吾

흘

웜

즐

$\Rightarrow$

氜

흥

茫

ले ฮี

总

已

पै

훙

D

过

एै

苟

을

동

ले वृ

$\Xi$ 믈

त्ञ

है क क

웅

I क

芩合

oi

ปิ

을 웅

률
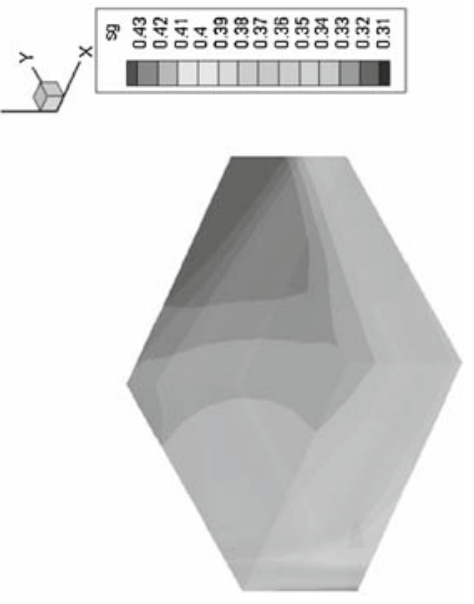


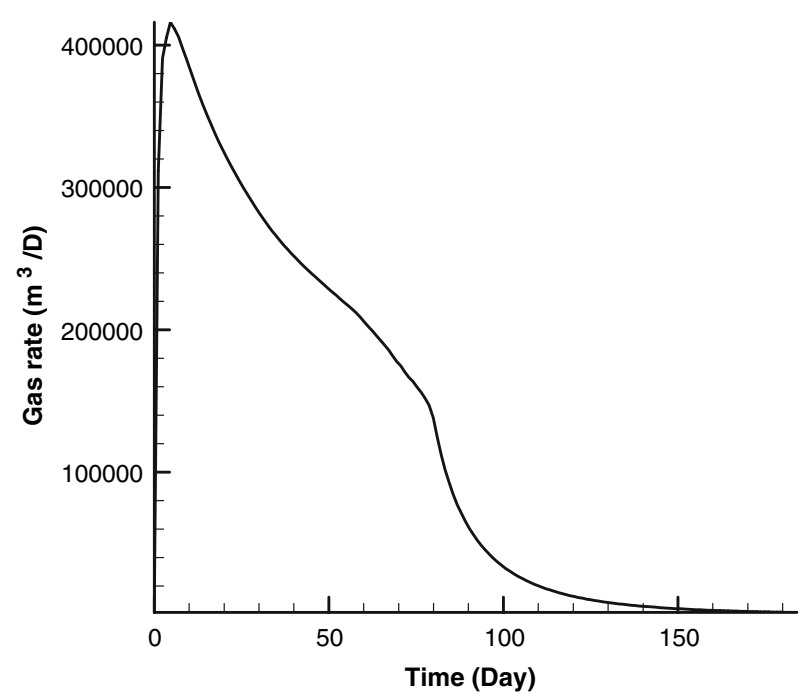

Fig. 8 The variation of gas rate with time in 3-D hydrate reservoir

Fig. 9 The variation of water rate with time in 3-D hydrate reservoir

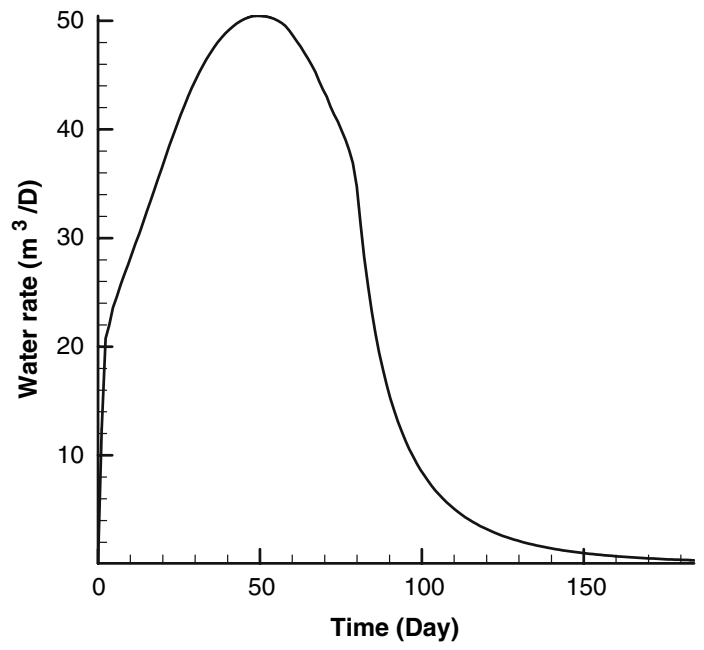

two aspects as follows. The primary reason is that the heat conductivity of hydrate-bearing formation including gas, water, ice, hydrate, and rock is relatively low, which restricts heat conduction. Therefore, the energy in surroundings can not transfer to the dissociation area to supply sufficient energy for further hydrate dissociation at a high rate. The other reason is that the free gas far away from the production well cannot flow to the vicinity of the well due to small pressure gradient, which also reduces the gas rate further. In the final stage, from the 80th day to the end in this case, gas rate decreases rapidly. At this stage, most hydrates have dissociated, which consume much sensible heat of formation, resulting in a low formation temperature. Thus, the dissociation of hydrate is slowed down, even interrupted. The low pressure at this stage also aggravates the reduction of gas rate. From the above analysis, we can see that field gas production from Class 3 hydrate reservoir only by depressurization may 


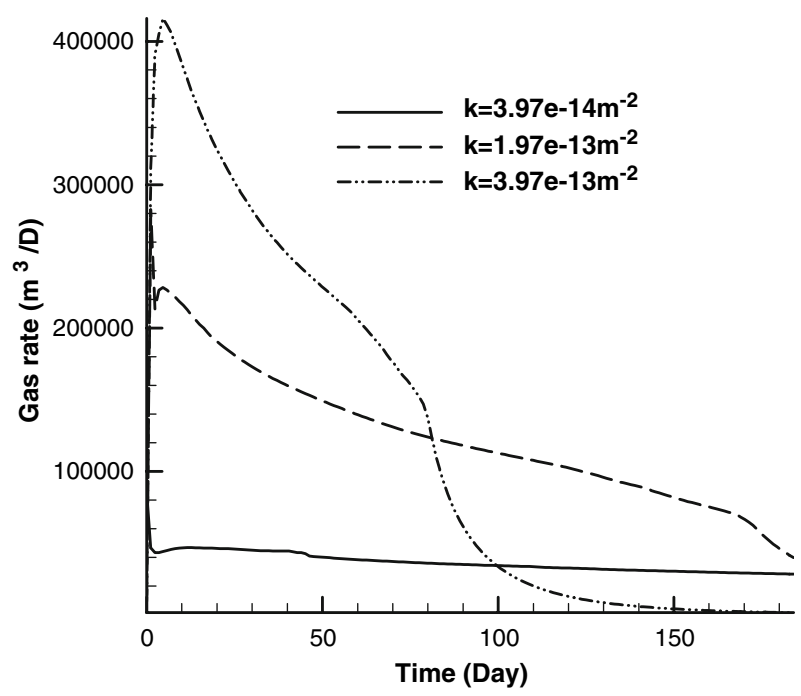

Fig. 10 The effect of absolute permeability on gas rate

cause energy deficiency for hydrate dissociation. We can reasonably deduce that the feasible method to exploit Class 3 hydrate reservoir may be to utilize depressurization initially and then switch to other methods such as thermal stimulation or inhibitor injection, etc.

The water rate can also be divided into three stages as shown in Fig. 9: the first stage is from the beginning to the 50th day, the second stage from the 50th day to the 80th day, and the third stage from the 80th day to the end in this case. At the first stage, the water rate rises to the largest value but the tendency is relatively slow compared with the gas rate. Under a large pressure gradient, the flow ability of gas is superior to water, thus, gas occupies more flow path than water and flows to the well before the water. Only a small part of the water can flow to the production well during the period from beginning to the 10th day. After gas rate reaches the largest value, it begins to decay which leads to increase of water flow. Water generated by hydrate dissociation also increases with the depletion of formation pressure. On the 50th day, water rate reaches the highest value. At the second stage, water rate reduces because the dissociation amount of hydrates reduces, which directly results in the decrease of water generated. At the same time, water freezing appears on the 46th day and more ice forms with the depressurizing, which transforms some liquid water into solid ice state. In the third stage, the formation pressure is low, water freezes seriously and water generated by hydrate is less, which causes a rapid decrease of water rate. In this case, the highest water rate is $50 \mathrm{~m}^{3} / \mathrm{d}$, which may imply that the de-water equipment is needed in field gas production from hydrate reservoir.

\subsection{Effect of Main Physical Parameters on Hydrates Dissociation}

In this section, the effects of some main physical variables such as absolute permeability, porosity, bottom pressure of production well, and hydrate saturation on gas, and water rates are analyzed. Taking the maximum absolute permeability of $3.97 \mathrm{E}-14 \mathrm{~m}^{2}, 1.97 \mathrm{E}-13 \mathrm{~m}^{2}$, and $3.97 \mathrm{E}-13 \mathrm{~m}^{2}$ as examples, the variations of gas and water rates with permeability are shown in Figs. 10 and 11. We can see that gas and water rates both increase with permeability, whereas the stable period of gas production reduces with the maximum absolute 


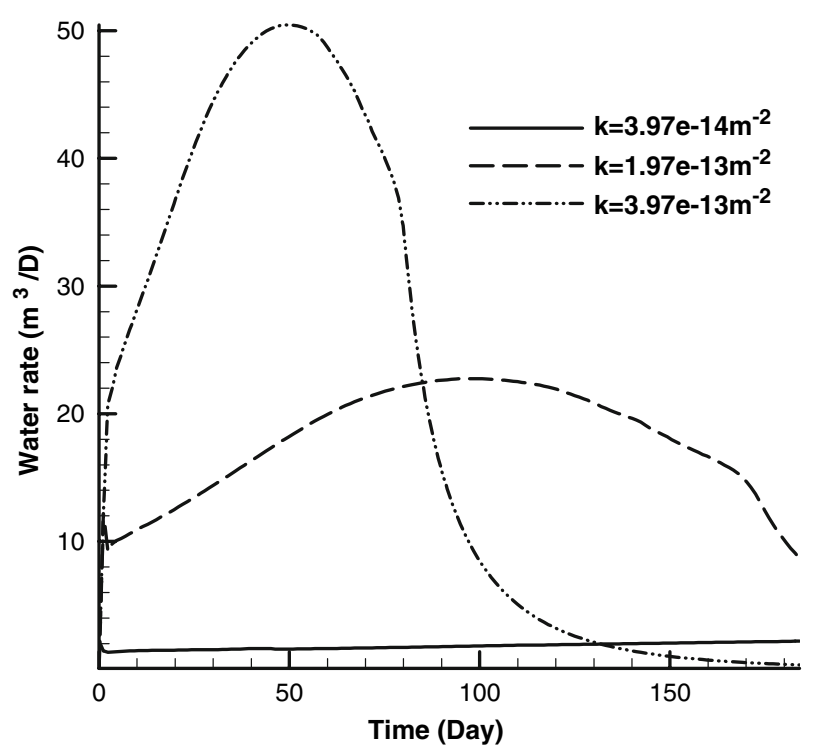

Fig. 11 The effect of absolute permeability on water rate

permeability. With the maximum absolute permeability of $3.97 \mathrm{E}-13 \mathrm{~m}^{2}$, the stable period of gas production is from the 10 th to the 80 th day. With the maximum absolute permeability of $1.97 \mathrm{E}-13 \mathrm{~m}^{2}$, the stable period lasts from the 10 th to the 170 th day. With the maximum absolute permeability of $3.97 \mathrm{E}-14 \mathrm{~m}^{2}$, the gas production in our concerned time span is always stable. Obviously, the higher the maximum absolute permeability, the earlier the water rate reaches its maximum. Therefore, we can think that the space interval of production well should be enlarged with the maximum absolute permeability.

Figures 12 and 13 show the variations of gas and water rates with time with the assigned porosities of $0.2,0.3$, and 0.35 . We can see that gas and water rates both decrease, and stable periods of gas and water production both prolong with the increase of porosity. In our cases, the other parameters are kept identical except for the porosity. Therefore, the amount of gas hydrate contained per unit volume sediment increases with porosity and the sensible heat contained per unit volume sediment reduces correspondingly because the specific heat of rock is higher than that of hydrates. These imply that more energy is need for gas dissociation in large porosity case, which will cause temperature decrease severely in per unit sediment. Numerical results show that with porosity of 0.2 , only a small area in reservoir is frozen and the maximum ice saturation is 0.4 . With porosity of 0.35 , most of reservoir area is frozen and the maximum ice saturation reaches up to 0.6. With the increase of porosity, hydrates dissociation slows under low temperature, and water flow capacity lowers due to the high ice saturation. The heat conductivity also decreases with porosity due to the low conductivity of hydrate, which further restricts the dissociation of hydrates.

Figures 14 and 15 show the variations of gas and water rates with time when the bottom pressures of production well are 1.0, 2.0, and $2.5 \mathrm{MPa}$, respectively. We can see that gas rate does not increase with the reduction of bottom pressure of production well as what we originally supposed to be. The variation of gas rate with bottom pressures does not show a clear law. However, water rate increases with the decrease of bottom pressure of production well. The reason is that under the low production pressure, hydrates dissociate quickly in a short 


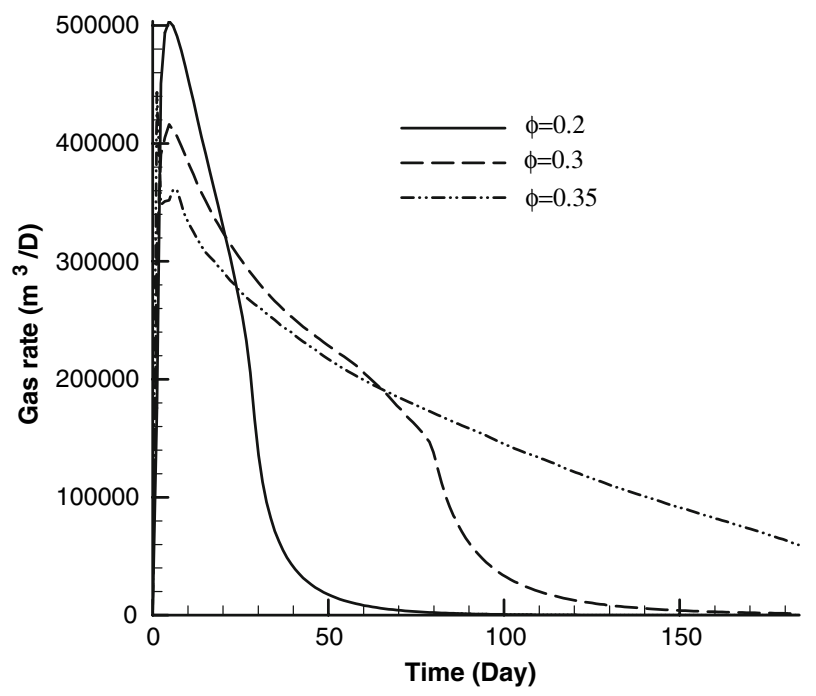

Fig. 12 The effect of porosity on gas rate

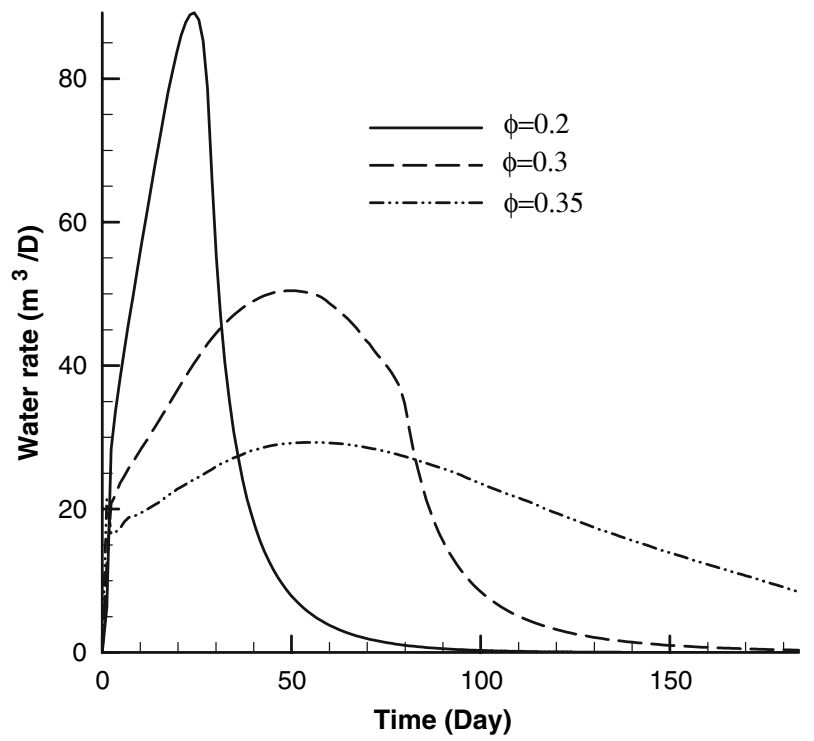

Fig. 13 The effect of porosity on water rate

time which consumes a large amount of energy contained in sediment. Due to the restriction of heat conductivity of hydrate-bearing sediment, the energy in surroundings cannot transfer to the areas with low temperature caused by hydrates dissociation, which may cause these areas to become frozen, resulting in blockage of some pore space. Numerical results show that with the bottom pressures equal to $2.5,2.0$, and $1.0 \mathrm{MPa}$, the corresponding maximum ice saturations are $0.16,0.38$, and 0.6 . Therefore, the bottom pressure of production well should be assigned an appropriate value in accordance to the reservoir characteristics rather than blindly reduced to a low value. 


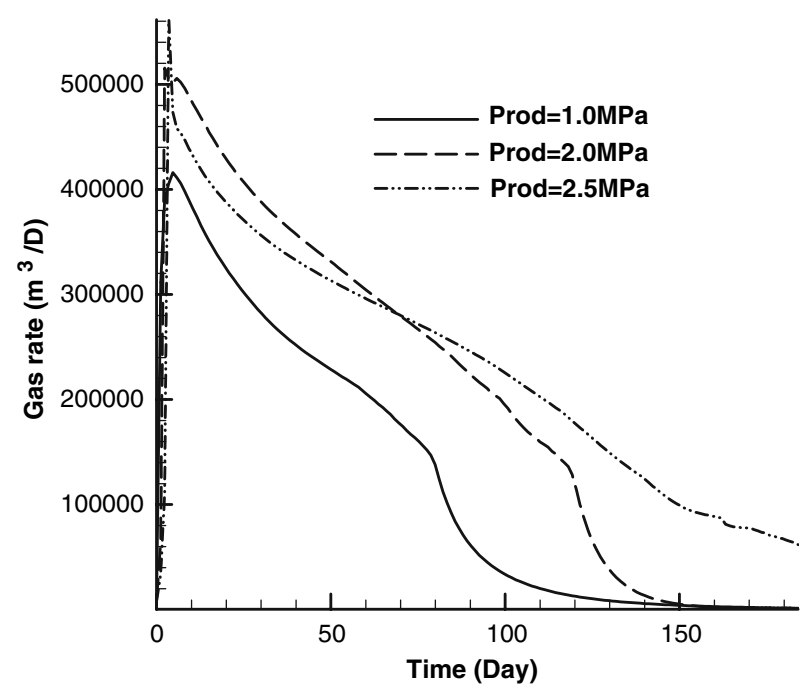

Fig. 14 The effect of bottom pressure on gas rate

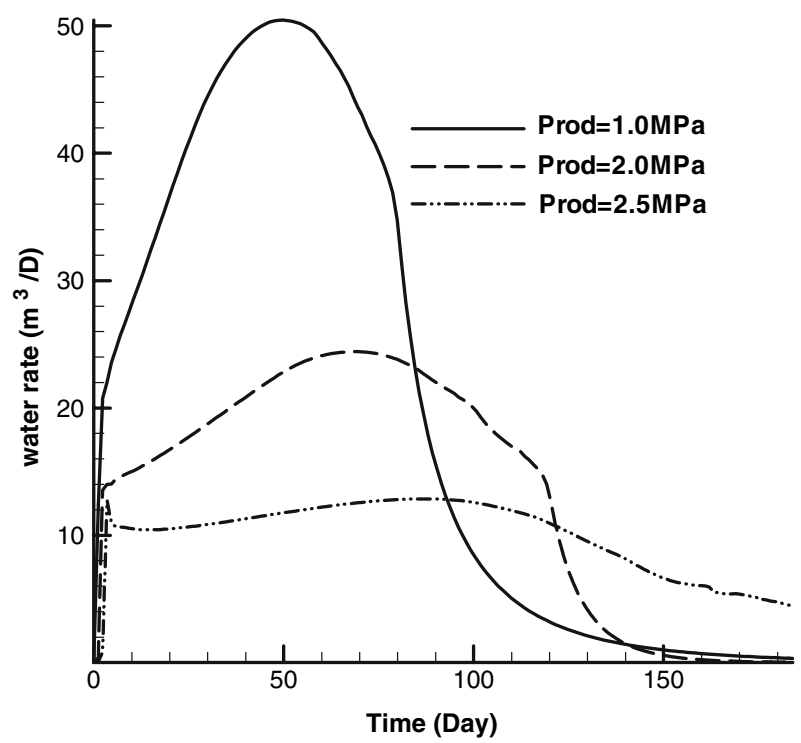

Fig. 15 The effect of bottom pressure on water rate

With hydrate saturations equal to $0.42,0.62$, and 0.72 , Figs. 16 and 17 demonstrate the variation of gas and water rates with time. We can see that when the gas rate is reduced, the stable period of gas production is prolonged and water rate increases with the increase of hydrate saturation. Numerical results show that when hydrate saturation is 0.42 , no ice appears in hydrate reservoir, which means the sensible heat contained in hydrate bearing sediment can supply enough energy for hydrates dissociation. When hydrate saturations are 0.62 and 0.72 , the corresponding maximum ice saturations are 0.6 and 0.72 , respectively. The reasons can be as follows: on the one hand, high hydrates saturation denotes low permeability 


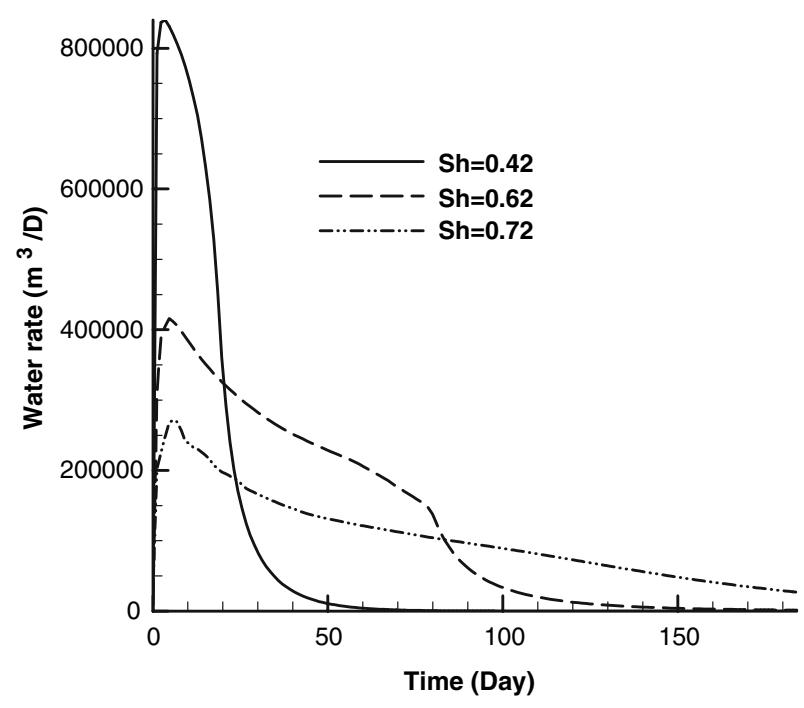

Fig. 16 The effect of hydrate saturation on gas rate

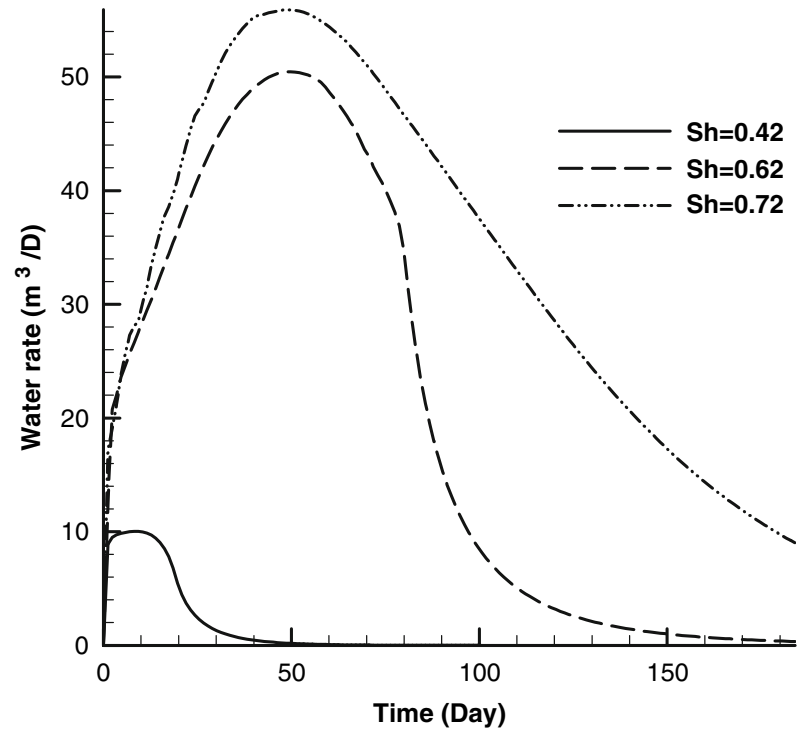

Fig. 17 The effect of hydrate saturation on water rate

which limits the pressure drops spreading in sediment, thus restricting the flow of initial free gas and reducing the dissociation zone and gas rate. On the other hand, high hydrate saturation indicates a large amount of energy needed for hydrate dissociation. However, the heat conductivity decreases with hydrate saturation, which may cause low temperature in sediment. Under low temperature, the driving force of hydrate dissociation reduces, which decreases the gas rate, but prolongs the stable period of gas production. The ice blockage of the flow path in porous media aggravates the reduction of the gas rate. 


\section{Simulation on Hydrate Reservoir of Class 1}

\subsection{Dynamic Process of Depressurization}

Now, let us consider, gas production from a hydrate zone underlain by a free gas zone (Class 1). The thickness, hydrate and water saturations, initial temperature and initial pressure of overlying hydrate zone are $30 \mathrm{~m}, 0.62,0.1,280 \mathrm{~K}$, and $6.0 \mathrm{MPa}$, respectively. The thickness, initial gas saturation, water saturation, and initial pressure of the underlain free gas zone are $30 \mathrm{~m}, 0.9,0.1$, and 6.0 MPa, respectively. The other relevant physical parameters are listed in Table 3.

Figure 18 shows the distributions of pressure, temperature, and saturations on the 116th day in overlying hydrate zone and underlain free gas zone in 3-D hydrate reservoir produced by depressurization in which the production well is located at the corner of the left-hand side and its bottom pressure is $1.0 \mathrm{MPa}$. Here, symbols pg, sw, sh, sg, si, and tenote pressure, water saturation, hydrate saturation, gas saturation, ice saturation, and temperature, respectively. Numerical results show that in the early stage, pressure is mainly depleted in the free gas zone because of its higher permeability than that of the hydrate zone. When gas pressure in the free gas zone is reduced to below the equilibrium pressure of hydrates at local temperature, hydrates in the interface between gas zone and hydrate zone begin to dissociate and the permeability increases accordingly. The temperature in this interface is also decreased because of the endothermic dissociation process of the hydrate phase change. The dissociation gas and water flow to the gas zone under the driving of vertical pressure difference due to different permeability distribution in vertical direction and the heat flows to the dissociation area from surroundings. The fluids flow and heat transfers under the generated pressure and temperature gradients to further accelerate hydrate dissociation. During the depressurization, ice first appears in the interface between hydrate zone and gas zone and then spreads upward into internal hydrate zone with the dissociation of hydrates. In general, hydrates dissociate mainly along two directions: vertical dissociation from the interface between hydrate zone and gas zone upward into the internal hydrate zone, radial dissociation from the well bore to the surroundings. Therefore, we can reasonably deduce that, if the target is to enhance gas production, then the hydrate interval should also be opened as that in the free gas zone. If the hydrate zone is the cap rock only, then in terms of safety of gas production, the hydrate zone should not be opened.

Figure 19 shows the variations of total gas rate and hydrate dissociation gas rate with time when the bottom pressure is $1 \mathrm{MPa}$. The so-called total gas rate is defined as the produced gas volume from production well per day $\left(\mathrm{m}^{3} /\right.$ day). The so-called hydrate dissociation gas rate is defined as gas volume generated by hydrates dissociation form production well per day $\left(\mathrm{m}^{3} /\right.$ day). Obviously, it is always less than the total gas rate. We can see that in early stage the total gas rate is very high, then decreases quickly and tends to a stable value with time because of the supplying gas generated by the hydrates dissociation in overlying hydrate zone. The hydrate dissociation gas rate can be divided into three stages in the case concerned. In the first stage lasting from the beginning to the 40th day, the hydrate dissociation gas rate increases and reaches up to its largest value. At this stage, with the depletion of pressure in gas zone, the driving force for hydrates dissociation increases, thus causing rapid hydrates dissociation. At the second stage from the 40th to the 160th day, the hydrate dissociation gas rate nearly remains stable. At this stage, though the temperature is lower than that the first stage, the dissociation extends to relatively large area with the pressure depletion in hydrate and free gas zones, which results in a stable dissociation gas rate and total gas rate. At the third stage from the 160th to the end, the hydrate dissociation gas rate decreases severely. At 

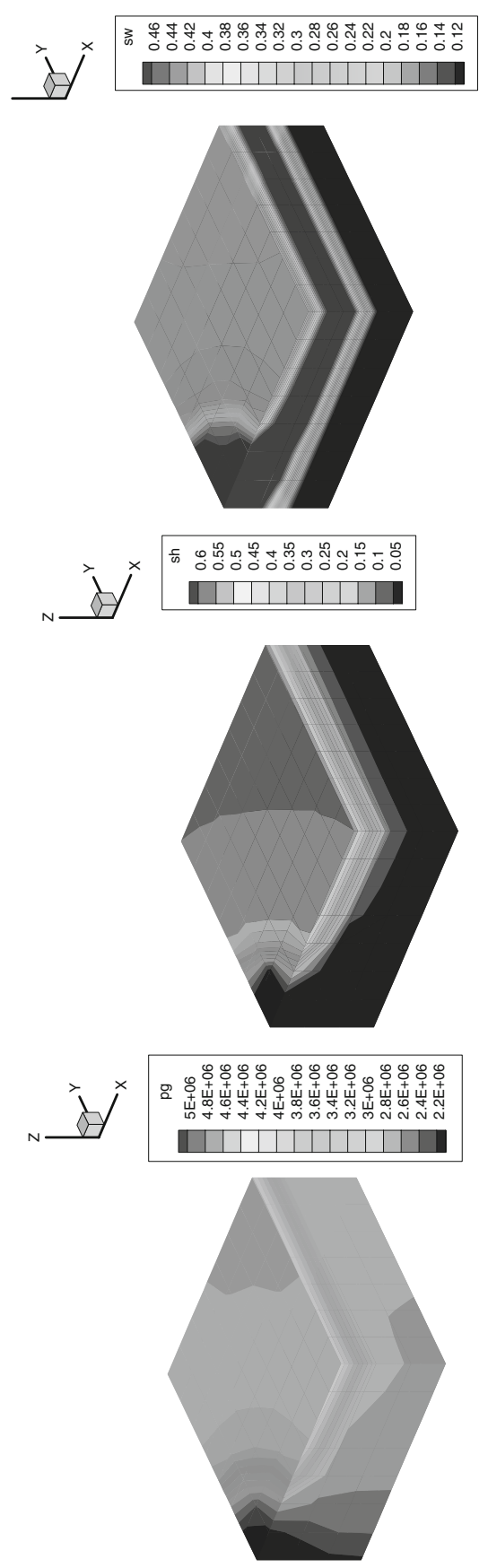
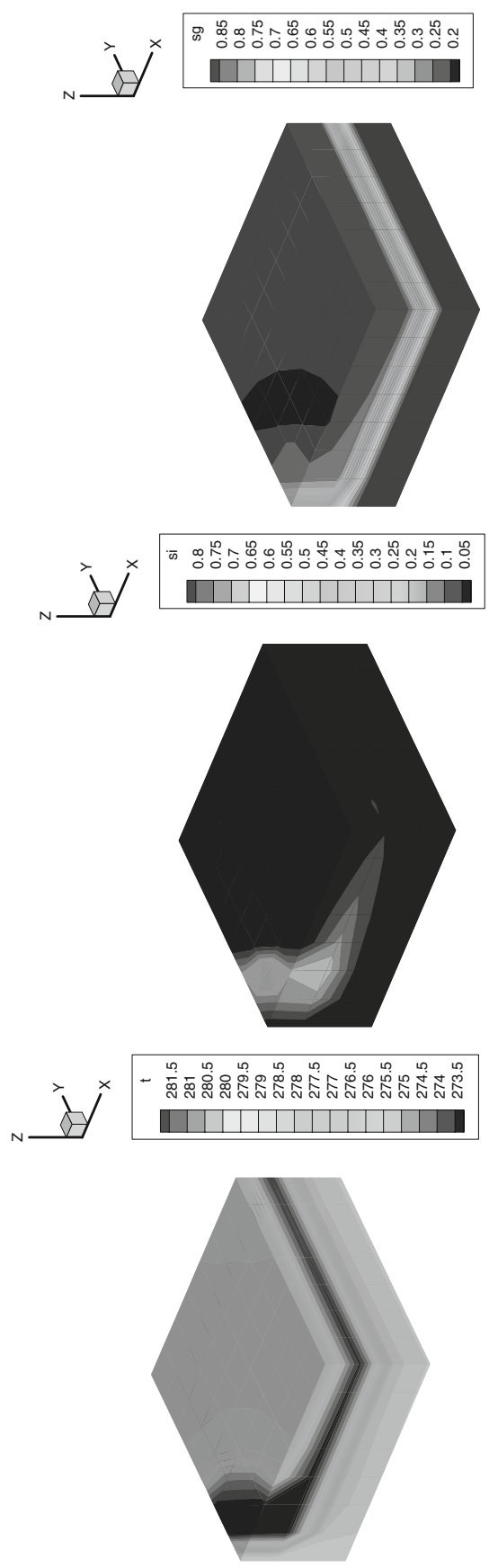

它.

$\exists$

눙

ป

氙

胥

ले

$\Xi$

ङ

㻤

on

Ð 은

웜

준

突

के

需

की

을

苞 oi

e

용

离会

ठ

$\Xi$ 먼

خิ

해

흐

돈

窇

ธี

올

응

है

苞

i

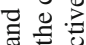

०

鞄

可

을을

음

ए ज :

$\exists 3$

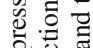

a

पे

㕸

을

롱

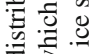

$\div \frac{1}{3}$

을.

$\infty$.

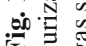




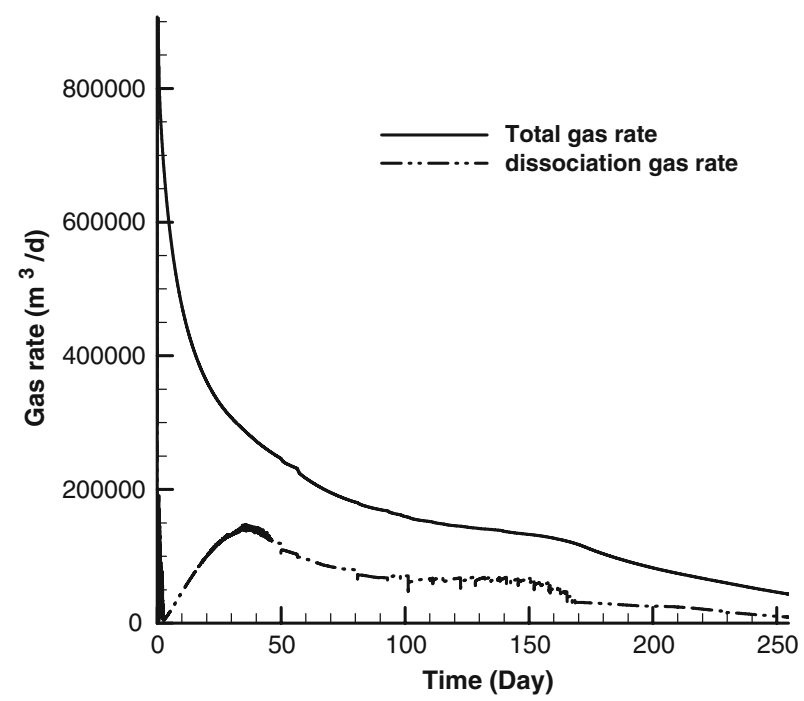

Fig. 19 The comparisons of total gas and dissociation gas rate under bottom pressure of $1.0 \mathrm{MPa}$

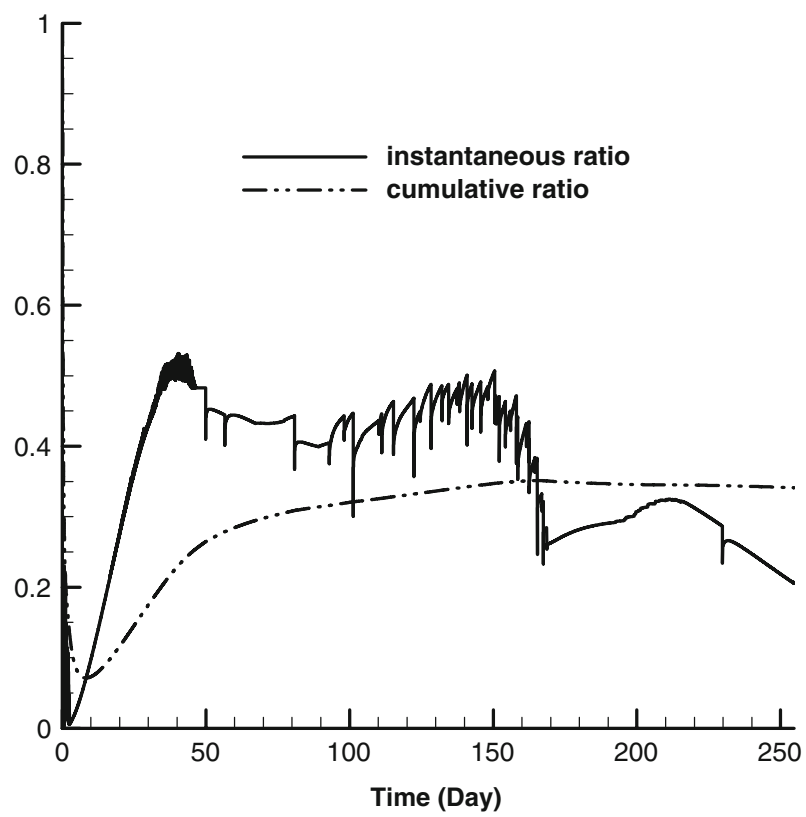

Fig. 20 The comparisons of instantaneous and cumulative ratios of dissociation gas volume under bottom pressure of $1.0 \mathrm{MPa}$

this stage, the temperature of hydrate zone is very low, which means the low phase equilibrium pressure of hydrate. Therefore, the driving force of hydrate dissociation is very small, resulting in the decrease of hydrate dissociation gas rate, and the total gas rate.

Figure 20 shows the variations of instantaneous ratio and cumulative ratio of dissociation gas volume with time when the bottom pressure is $1.0 \mathrm{MPa}$. The instantaneous ratio of 


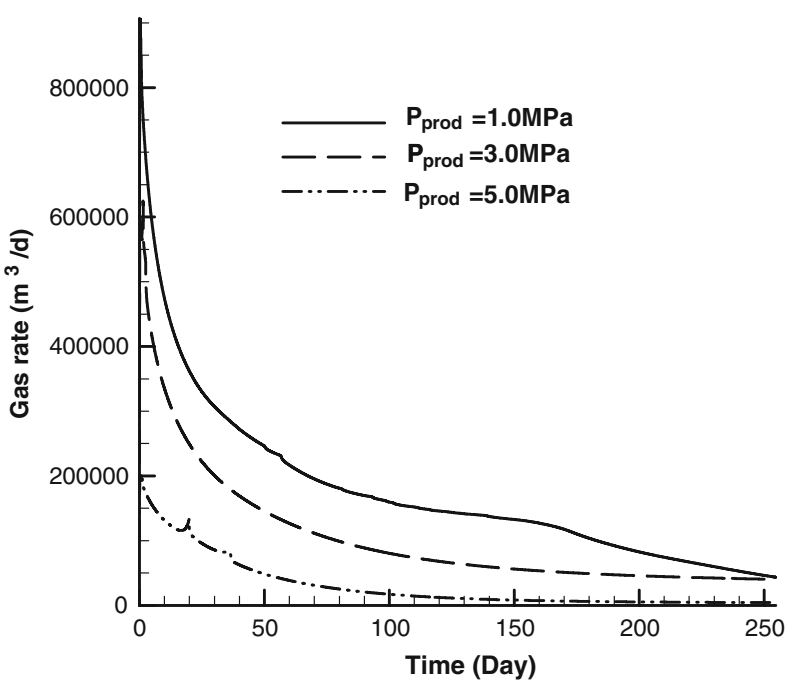

Fig. 21 The comparisons of gas rate under different bottom pressure

dissociation gas volume is defined as the ratio of the dissociation gas rate to the total gas rate. The cumulative ratio of dissociation gas volume is defined as the ratio of cumulative volume of dissociation gas to cumulative gas volume. We can see from Fig. 20 that with the production of gas, the instantaneous ratio of dissociation gas volume reaches its maximum value of 0.5 on the 40th day, then nearly maintains the stable value to the 160th day, and rapidly decreases to about 0.2 . The cumulative ratio of dissociation gas volume is up to $35 \%$, which implies that the overlying gas hydrate zone can apparently enhance gas rate and prolongs the life span of gas reservoir.

\subsection{Effect of Bottom Pressure of Production Well}

Figures 21 and 22 show the comparisons of gas and water rates with bottom pressure equal to 1,3 , and $5 \mathrm{MPa}$. We can see that gas and water rates both increase with the decrease of bottom pressure. When the bottom pressure is $5 \mathrm{MPa}$, water is not produced at the early stage from the beginning to the 20th day. The reasons are that the water mobility is relatively weak under small pressure gradient due to high bottom pressure, especially with the small water saturation assigned. On the other hand, only a small part of hydrates dissociate at the early stage, indicating that less water is produced.

Figure 23 shows the comparisons of dissociation gas rate with bottom pressure equal to 1,3 , and $5 \mathrm{MPa}$. We can see that, the dissociation gas rate increases with the decrease of bottom pressure. The reason is that the initial free gas is quickly produced under low bottom pressure, which causes the pressure drops to spread fast in reservoir zones, resulting in a large amount of hydrates dissociation in an extensive area. Figure 24 shows the comparisons of instantaneous ratio of dissociation gas volume with bottom pressure equal to 1, 3, and $5 \mathrm{MPa}$. It can be found that the maximum instantaneous ratios of dissociation gas volume under different bottom pressures are nearly the same, though the time up to the maximum value is different. In our cases, the times that the instantaneous ratio reaches up to the maximum value are, respectively, the 40th, 60th, and 200th day. Numerical results also show that cumulative volume of dissociation gas increases with the reduction of bottom pressure. 


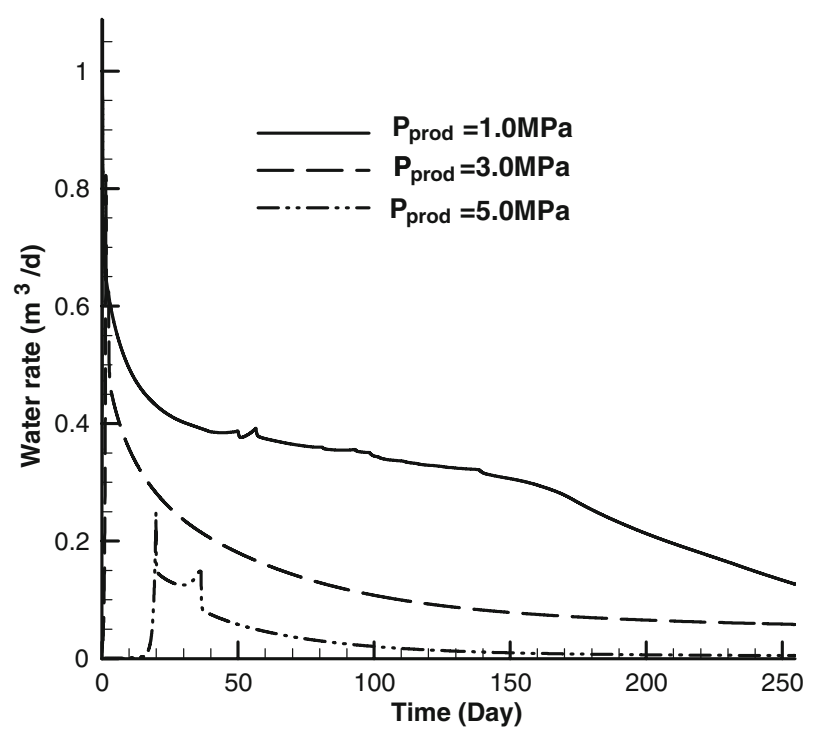

Fig. 22 The comparisons of water rate under different bottom pressure

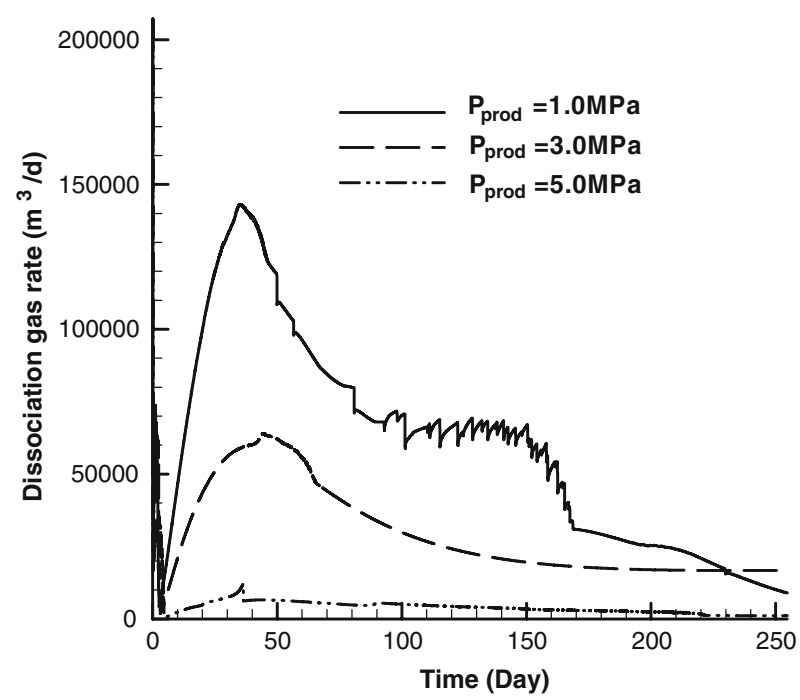

Fig. 23 The comparisons of dissociation gas rate under different bottom pressure

In filed production for the hydrate reservoir of Class 1, a too high pressure difference between reservoir and bottom of production well will lead to some problems, e.g., sanding, equipment eroding, and early-water breakthrough. However, too small pressure difference will limit hydrates dissociation as mentioned above. Therefore, the ideal production method for Class 1 is that the high bottom pressure is first used for an appropriate period and then the low bottom pressure is considered. We take case1, case2, and case 3 as three examples to analyze the gas and water rates. To compare conveniently, the bottom pressure from the 


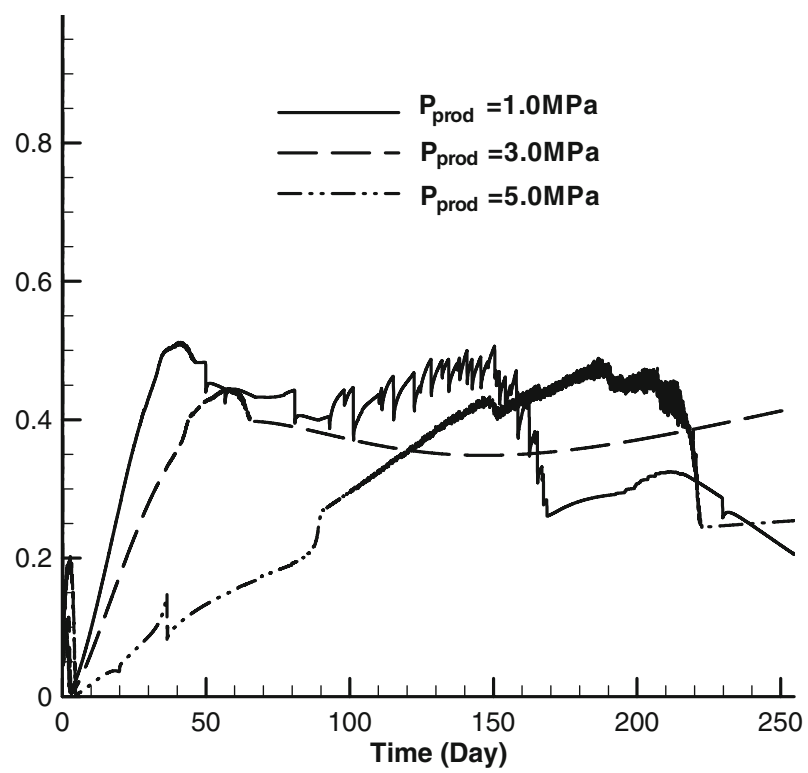

Fig. 24 The comparisons of instantaneous ratio of dissociation gas volume under different bottom pressure

beginning to the 70th day are all assigned as $5 \mathrm{MPa}$ in these cases, and from the 70th day to the end, the bottom pressures are in turn adjusted as 1,2, and $3 \mathrm{MPa}$ for case1, case2, and case3, respectively.

Figure 25(a-d) shows the comparisons of gas rate, water rate, dissociation gas rate, and cumulative ratio of dissociation gas volume for case1, case2, and case 3 , respectively. We can see that from the beginning to the 74th day all the data are the same for three cases. The gas rate decreases rapidly, dissociation gas rate is very low, and the instantaneous and cumulative ratios of dissociation gas volume are respectively only 0.2 and $10 \%$ because of the small pressure difference. After the bottom pressure is adjusted, the gas rate and water rate immediately increase and reach up to the maximum values. The lower the bottom pressure, the higher the rate is. The dissociation gas rate also increases with the decrease of bottom pressure. However, the dissociation gas rate reaches the maximum on the 100th day rather than immediately. The cumulative ratio of dissociation gas volume increases with the reduction of bottom pressure. For case 1, the cumulative ratio of dissociation gas volume reaches $35 \%$, indicating the overlying hydrate zone can apparently improve gas production.

\section{Conclusions}

In this article, the experimental study and numerical simulations of hydrate dissociation are carried out. A mathematical model is developed to interpret the hydrate dissociation by depressurization in hydrate-bearing porous media. The model can explain the effects of the flows of multiphase fluid, the kinetic, and the endothermic process of hydrate dissociation, ice-water phase transition, convection and conduction on the hydrate dissociation, and gas and water production. The numerical results of 1- and 2-D hydrate dissociation systems are 

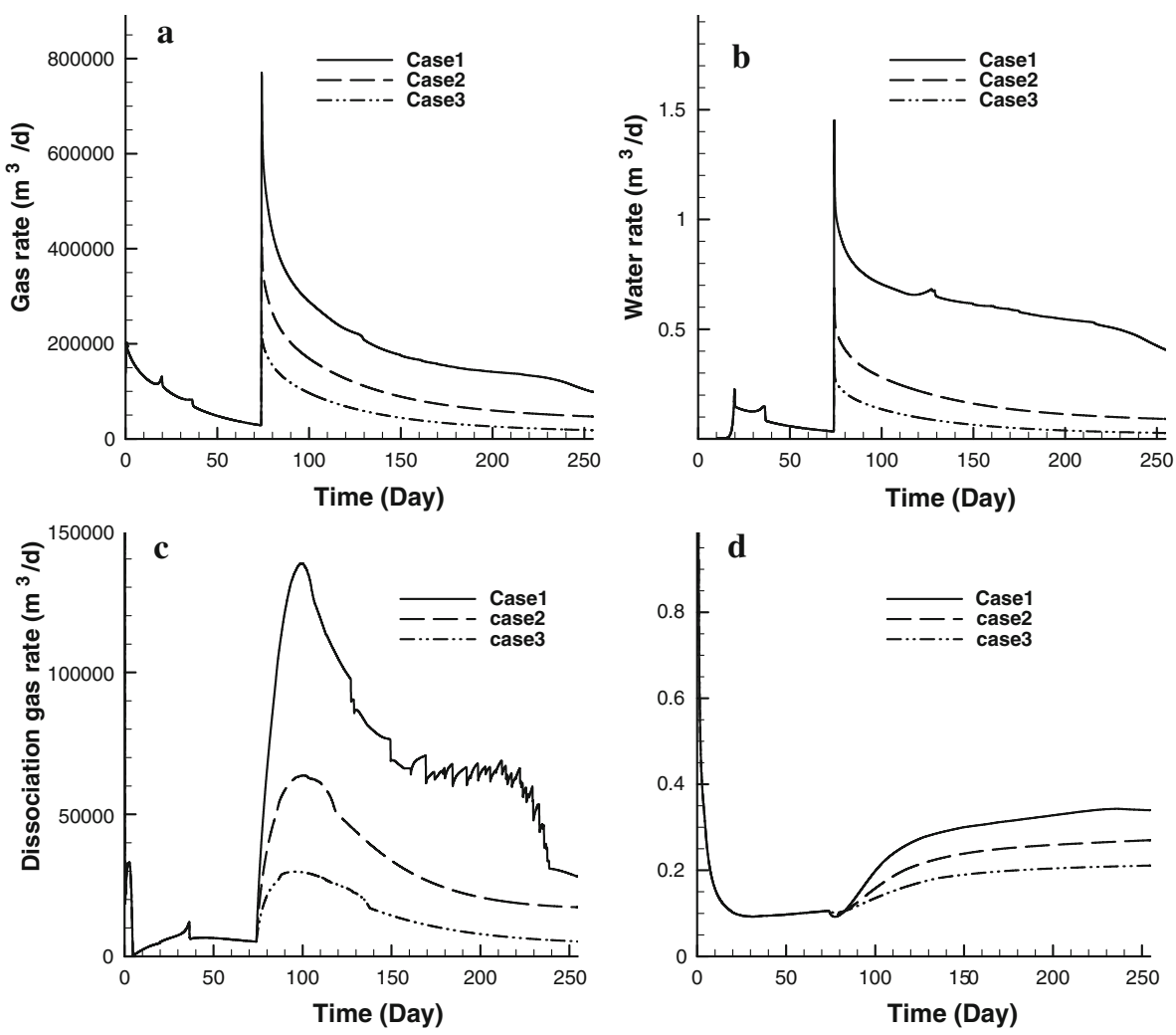

Fig. 25 The comparisons of gas rate, water rate, dissociation gas rate, and cumulative ratio of dissociation gas volume under different bottom pressures

consistent with the experiments, which completes the verification of the mathematical model and numerical solution proposed in this study.

Based on this verification, a 3-D hydrate reservoir of Class 3 by depressurization is studied. The evolutions of pressure, temperature, saturations of water, ice, gas, and hydrates are presented. The effects of some main physical parameters on gas and water rates are analyzed. The results show that gas production from hydrate reservoir of Class 3 only by depressurization in field may cause energy deficiency for hydrate dissociation. We can reasonably deduce that the feasible method to exploit hydrate reservoir of Class 3 may be to adopt depressurization initially and then switch to other methods such as thermal stimulation or inhibitor injection, etc. Computational results may also imply that the de-water equipment is needed in field gas production from hydrate reservoir.

Gas production from a hydrate zone underlain by a free gas zone (Class 1) by depressurization is numerically studied. The evolutions of pressure, temperature, saturations of water, ice, gas, and hydrates in hydrate zone and gas zone are elucidated and such physical parameters as gas and water rates, and dissociation gas rate in 3-D hydrate reservoir are presented. The effects of bottom pressure of well bore on gas rate, water rate, dissociation gas rate, instantaneous ratio, and cumulative ratio of dissociation gas volume are analyzed. Results show that the overlying gas hydrate zone can apparently enhance gas rate and prolong the life span of gas reservoir. 
Acknowledgments This work is financially supported by the National High Technology Research and Development Program of China (863 Program, Grant No. 2006AA09A209) and the National Basic Research Program of China (Grant No. 2009CB219507).

\section{References}

Ahmadi, G., Ji, C., Duane, H.S.: Numerical solution for natural gas production from methane hydrate dissociation. J. Pet. Sci. Eng. 41, 169-185 (2004). doi:10.1016/j.profnurs.2003.09.004

Bai, Y.H., Li, Q.P., Yu, X.C., Feng, G.Z.: Numerical study on the dissociation of gas hydrate and its sensitivity to physical parameters. China Ocean. Eng. 21(4), 625-636 (2007)

Burshears, M., Obrien, T.J., Malone, R.D.: A multi-phase, multi-dimensional, variable composition simulation of gas production from a conventional gas reservoir in contact with hydrates. SPE 15246, 449-453 (1986)

Civan, F.C.: Scale effect on porosity and permeability: kinetics, model and correlation. AIChE J. 47(2), 271287 (2001). doi:10.1002/aic.690470206

Holder, G.D., Patrick, F.A.: Simulation of gas production from a reservoir containing both gas hydrate and free natural gas. SPE 11105, 1-4 (1982)

Ji, C., Ahmadi, G., Smith, D.H.: Constant rate natural gas production from a well in a hydrate reservoir. Energy Convers. Manage. 44, 2403-2423c (2003). doi:10.1016/S0196-8904(03)00010-4

Kamath, V.: Study of heat transfer characteristics during dissociation of gas hydrate in porous media. Ph.D thesis, University of pittsburgh, Pittsburgh (1983)

Kim, H.C., Bishnoi, P.R., Heidemann, R.A., Rizvi, S.S.H.: Kinetics of methane hydrate dissociation. Chem. Eng. Sci. 42(7), 1645-1653 (1987). doi:10.1016/0009-2509(87)80169-0

Kvenvolden, K.A.: A primer on the geological occurrence of gas hydrate. Geol. Soc. London Spec. Publ. 137, 930 (1998)

Lake, L.W.: Enhanced Oil Recovery. Prentice-Hall Inc., Upper Saddle River, NJ (1989)

Makogon, Y.F.: Hydrate of Hydrocarbons. PennWell Publishing Co., Tulsa, Oklahomac (1997)

Moridis, G.J.: Numerical studies of gas production from methane hydrates. SPE 87330, 1-11 (2002)

Moridis, G.J., Timothy, S.C.: Strategies for gas production from hydrate accumulations under various geological and reservoir conditions. Proceedings, TOUGH Symposium 2003, Lawrence Berkeley National Laboratory, Berkeley, California, May 12-14 (2003)

Nazridoust, K., Ahmadi, G.: Computational modeling of methane hydrate dissociation in a sandstone core. Chem. Eng. Sci. 62, 6155-6177 (2007). doi:10.1016/j.ces.2007.06.038

Sloan, E.D.: Clathrate hydrates of natural gases, Second edition. Marcel Deckker Inc., New York (1998)

Sun, X., Nanchary, N., Mohanty, K.K.: 1-D modeling of hydrate depressurization in porous media. Transp. Porous Media 58, 315-338 (2005). doi:10.1007/s11242-004-1410-x

Sun, X.F., Kishore, K.M.: Kinetic simulation of methane hydrate formation and dissociation in porous media. Chem. Eng. Sci. 61, 3476-3495 (2006). doi:10.1016/j.ces.2005.12.017

Tang, L.G., Li, X.S., Feng, Z.P., et al.: Control mechanisms for gas hydrate production by depressurization in different scale hydrate reservoirs. Energy Fuels 21(1), 227-233 (2007). doi:10.1021/ef0601869

Tsypkin, G.G.: Regimes of dissociation of gas hydrates coexist with a gas in natural strata. J. Eng. Phys. Thermophys. 74(5), 1083-1089 (2001). doi:10.1023/A:1012999310268

Wu, S.G., Yao, B.C.: Geologic structure and resource evaluation of gas hydrate. Beijing: Science Press (2008). (in Chinese)

Yousif, M.H., Abass, H.H., Selim, M.S., Sloan, E.D.: Experimental and theoretical investigation of methanegas-hydrate dissociation in porous media. SPE 18320, 69-76 (1991) 